\title{
An assessment of human resources for health hiring, deployment and retention, procedures and practices in Cross river and Bauchi states, Nigeria
}

Osasuyi Dirisu

Population Council

Akinwumi Akinola

Population Council

Ekechi Okereke

Population Council

Godwin Unumeri

Population Council

Ibrahim Suleiman

Population Council

See next page for additional authors

Follow this and additional works at: https://knowledgecommons.popcouncil.org/departments_sbsr-rh

Part of the Civic and Community Engagement Commons, Demography, Population, and Ecology Commons, Family, Life Course, and Society Commons, and the International Public Health Commons How does access to this work benefit you? Let us know!

\section{Recommended Citation}

Dirisu, Osasuyi, Akinwumi Akinola, Ekechi Okereke, Godwin Unumeri, Ibrahim Suleiman, Aisha Jibril, and George I. Eluwa. 2019. "An assessment of human resources for health hiring, deployment and retention, procedures and practices in Cross river and Bauchi states, Nigeria." Abuja: Population Council. 
Authors

Osasuyi Dirisu, Akinwumi Akinola, Ekechi Okereke, Godwin Unumeri, Ibrahim Suleiman, Aisha Jibril, and George I. Eluwa

This report is available at Knowledge Commons: https://knowledgecommons.popcouncil.org/departments_sbsr-rh/ 


\section{POPULATION}

COUNCIL

ASSESSMENT OF HUMAN RESOURCES FOR HEALTH HIRING, DEPLOYMENT AND RETENTION, PROCEDURES AND PRACTICES IN NIGERIA'S CROSS RIVER AND BAUCHI STATES

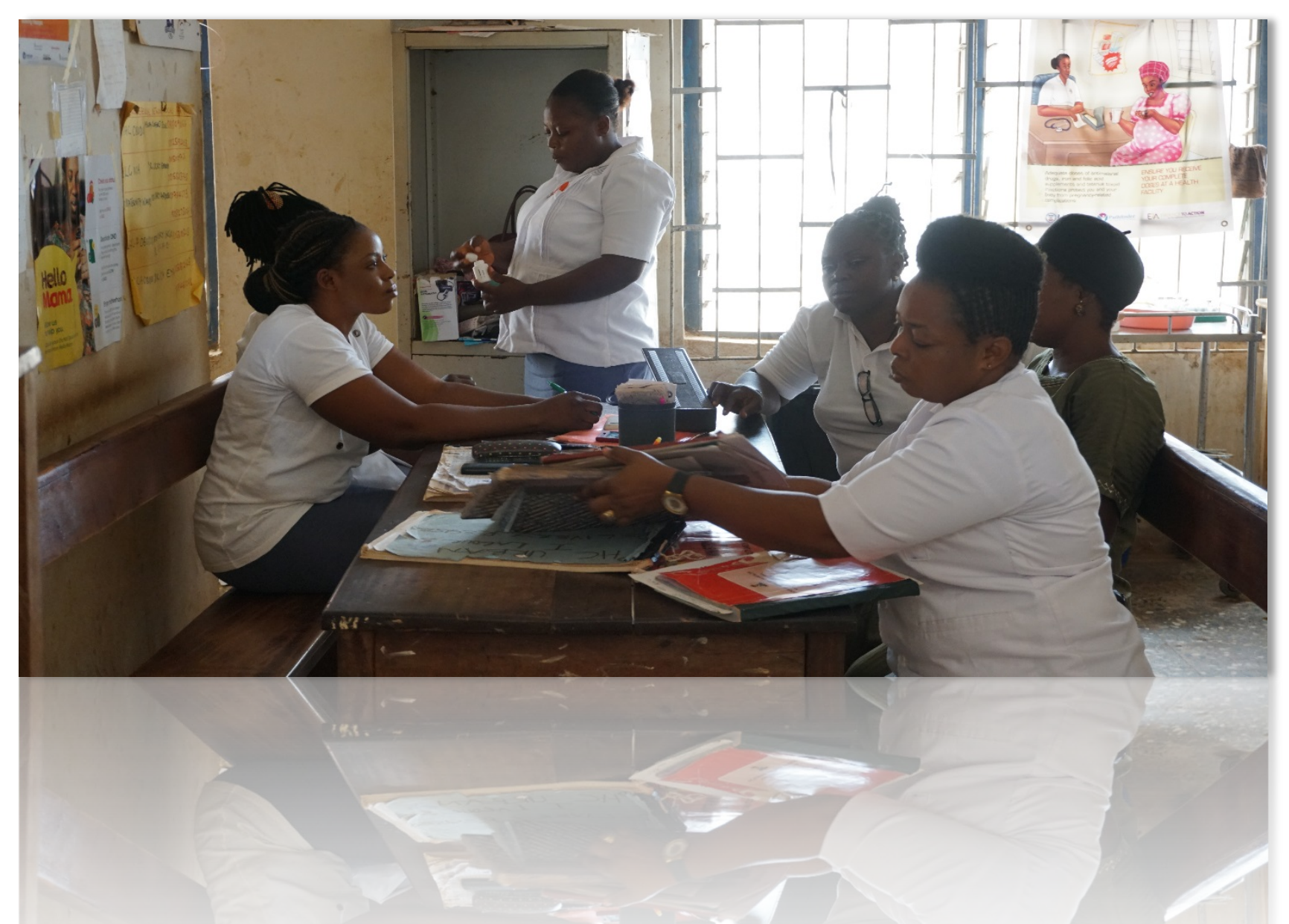


Ideas. Evidence. Impact.

The Population Council confronts critical health and development issues-from stopping the spread of HIV to improving reproductive health and ensuring that young people lead full and productive lives. Through biomedical, social science, and public health research in 50 countries, we work with our partners to deliver solutions that lead to more effective policies, programs, and technologies that improve lives around the world. Established in 1952 and headquartered in New York, the Council is a non-governmental, non-profit organization governed by an international board of trustees.

Population Council

Nigeria Country Office

No. 16, House 4, P.O.W. Mafemi Crescent

Utako, FCT Abuja

Nigeria

Tel: +23492914878

popcouncil.org

Suggested Citation -Dirisu Osasuyi, Akinola Akinwumi, Okereke Ekechi, Unumeri Godwin, Suleiman Ibrahim, Jibril Aisha and Eluwa George 2019. "An assessment of human resources for health hiring, deployment and retention, procedures and practices in Cross river and Bauchi states, Nigeria”. Human Resources for Health (HRH) Project: Population Council

(C) 2019 The Population Council, Inc.

Disclaimer

The views and opinions expressed in this report do not necessarily reflect the views of the donor, Global Affairs Canada (GAC), for the Enhancing the Ability of Frontline Health Workers to Improve Health in Nigeria Project. 


\section{Table of Contents}

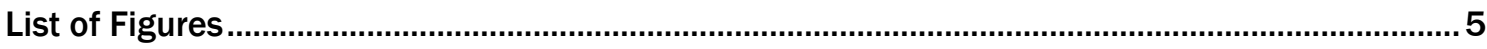

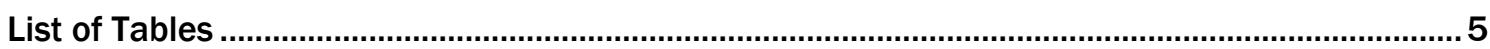

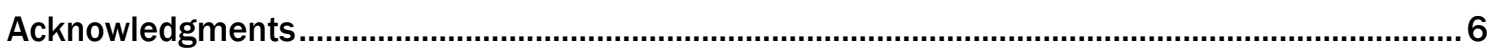

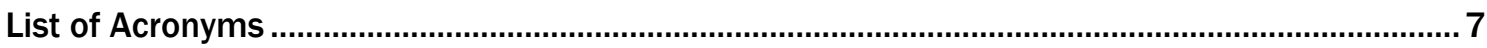

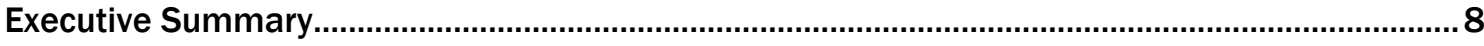

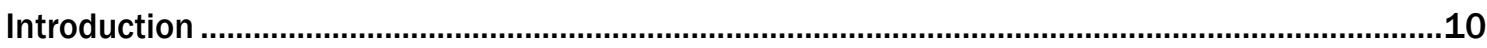

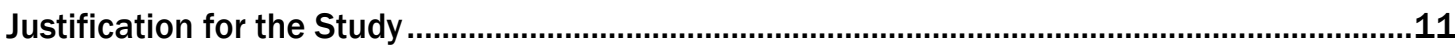

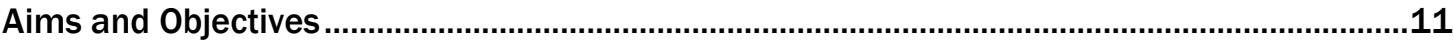

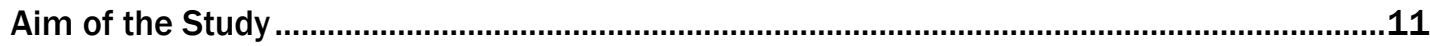

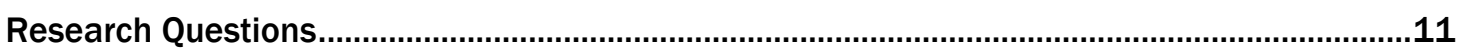

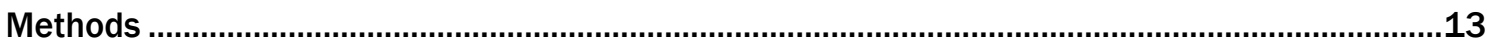

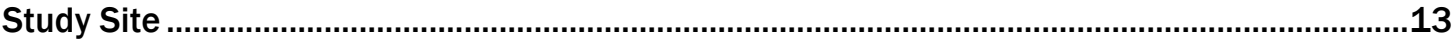

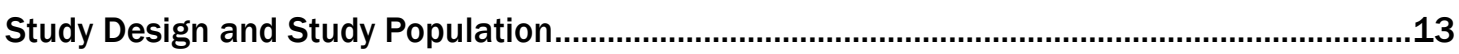

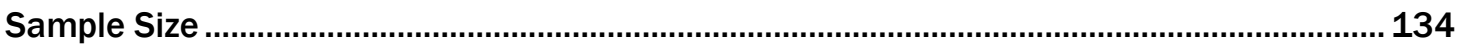

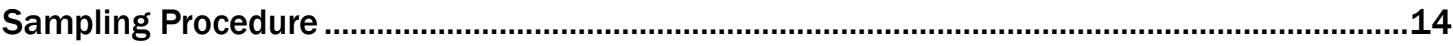

Development of Instruments: Interview Guides and Survey Questionnaires ...........................15

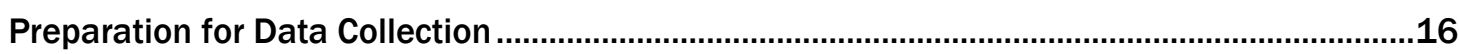

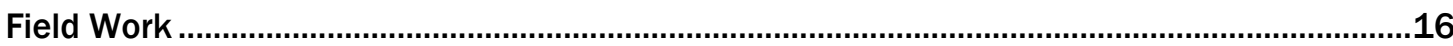

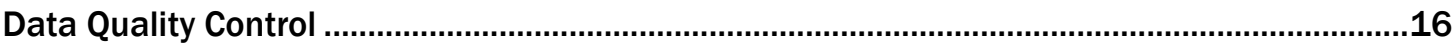

Data Processing and Analysis.......................................................................................

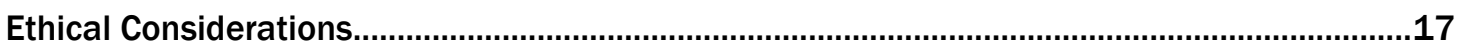

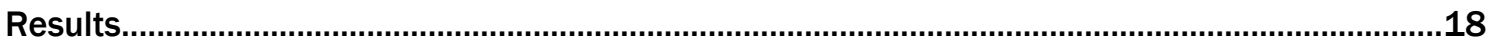

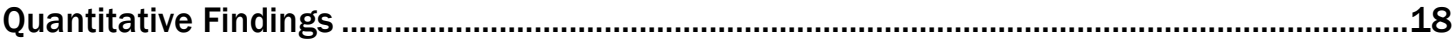

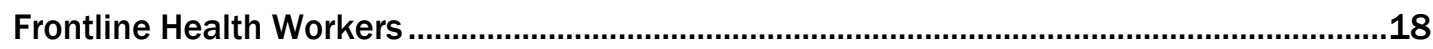

Socio-demographic and Background Characteristics ...................................................... 18

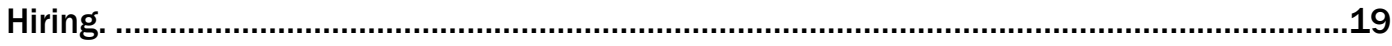

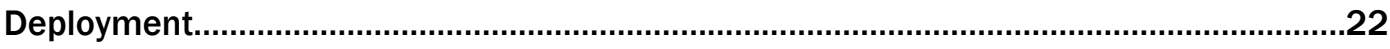

Gender Considerations in Hiring and Deployment........................................................22

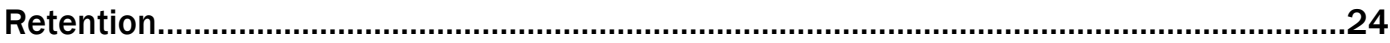

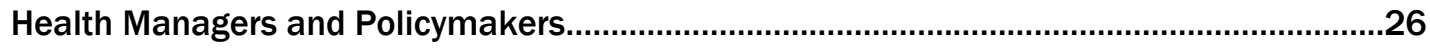

Socio-demographic and Background Characteristics........................................................26

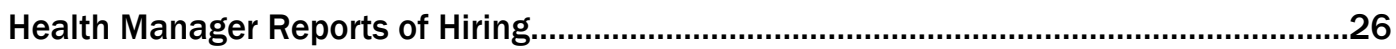

Health Manager Reports of Deployment Policies and Practices.........................................30

Health Manager Reports of Retention ......................................................................... 31

Manager Perceptions of Worker Satisfaction and Facility Performance...........................32

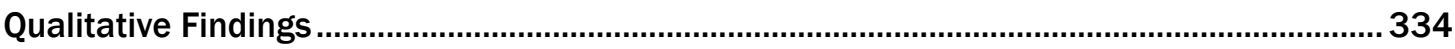

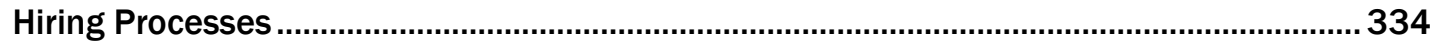

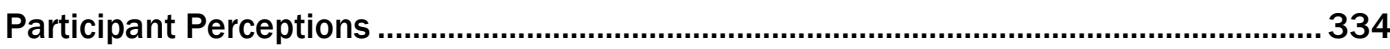




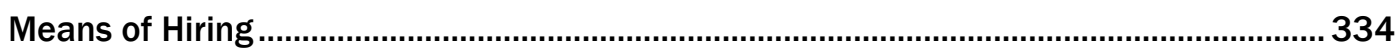

Experiences with the Hiring Process............................................................................ 334

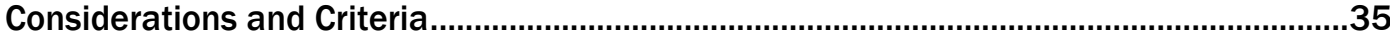

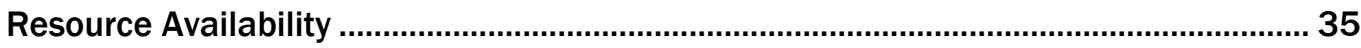

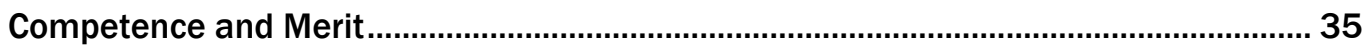

Equal Opportunity: Ethnicity, Gender and Quota system ............................................. 36

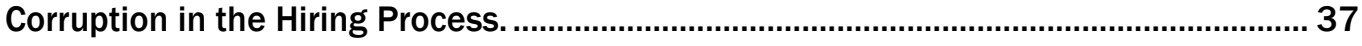

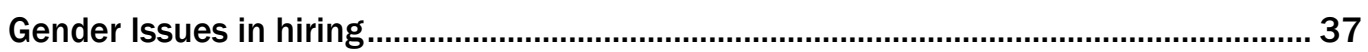

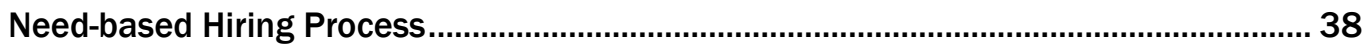

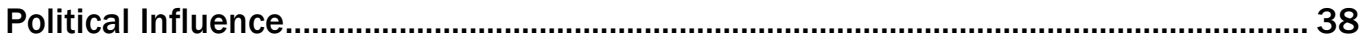

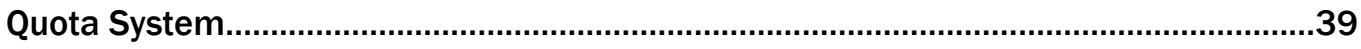

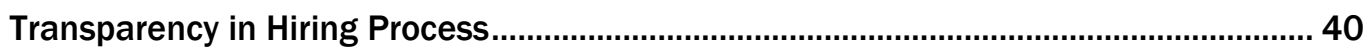

Rating of Hiring Process...................................................................................................40

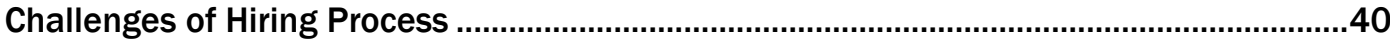

Discrimination and Political Influence.................................................................................. 40

Embargo on Employment .................................................................................................... 41

Poor Health Sector Funding......................................................................................... 41

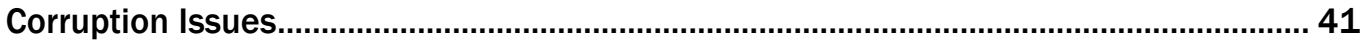

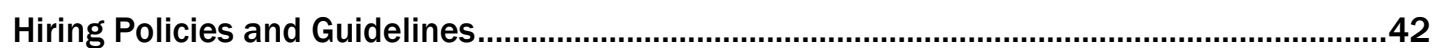

Awareness of Policies .......................................................................................................42

Documentation and Scope of Policies and Guidelines................................................... 42

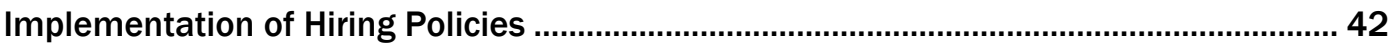

Barriers to Policy Implementation.................................................................................. 43

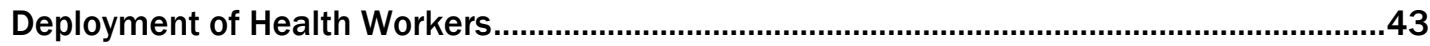

Factors Affecting Health Worker Posting Decisions .............................................. 43

General Considerations for Health Worker Posting .......................................................... 445

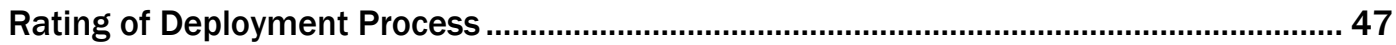

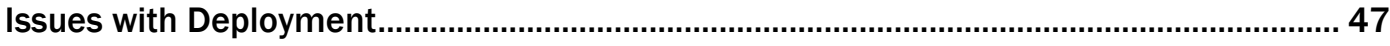

Consequences and Disciplinary Measures for Posting Non-Compliance........................... 48

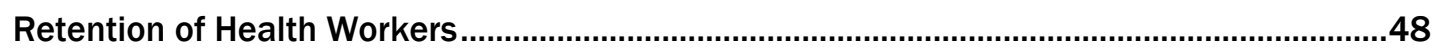

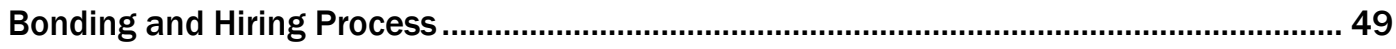

Task Shifting Policy ............................................................................................................... 50

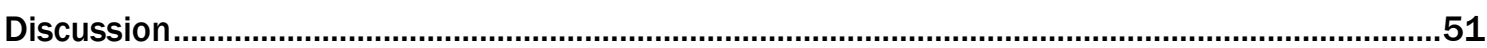

Hiring Practices and Procedures in the State..............................................................................51

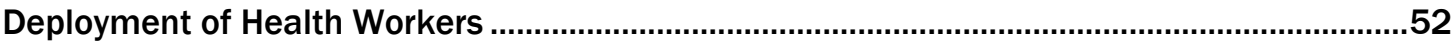

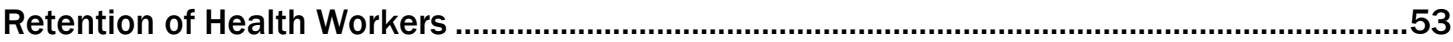

Policy Recommendations and Conclusion .............................................................................54

Recommendations for Policy and Practice ............................................................................54

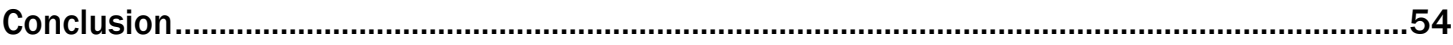

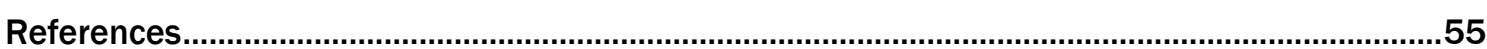




\section{List of Figures}

Figure 1: Study Location: Bauchi and Cross River States

\section{List of Tables}

Table 1: Survey Participants in Bauchi and Cross River States ..............................................13

Table 2: Selected Local Government Areas from Each Senatorial Zone

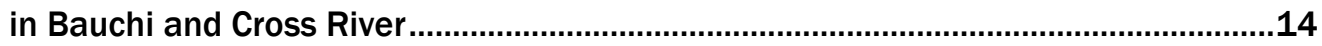

Table 3: Study Instruments, Participants and Issues Addressed in Each Instrument .............15

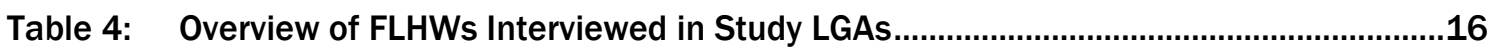

Table 5: Socio-demographic Characteristics of Health Workers .............................................18

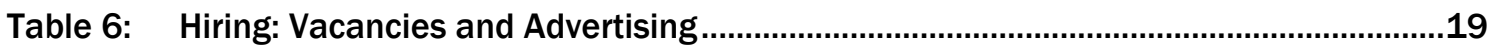

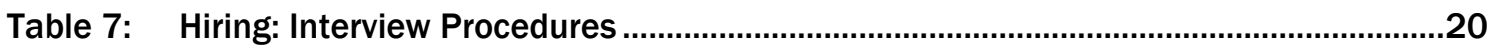

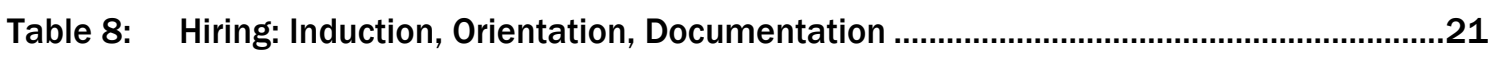

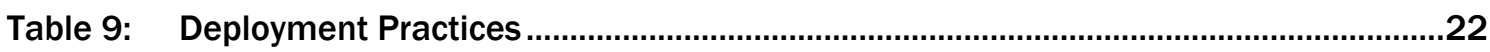

Table 10: Gender Preferences and Considerations in Hiring and Deployment ..........................23

Table 11: Retention of Health Workers: Staff Workloads........................................................24

Table 12: Retention of Health Workers: Remuneration, Incentives, Compensation...................25

Table 13: Socio-demographic and Background Characteristics of Health Managers

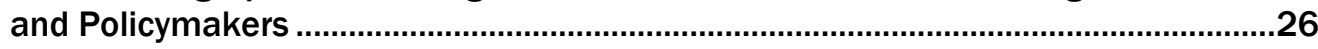

Table 14: Health Manager Reports of Hiring: Policy Implementation and Practices.................27

Table 15: Health Manager Reports of Hiring: Job Advertising and Application Process............28

Table 16: Health Manager Reports of Hiring: Interview and Documentation Process...............29

Table 17: Health Manager Reports on Deployment Policies and Practices ................................30

Table 18: Health Manager Reports of Retention: Policy Implementation and Incentives ........31 


\section{Acknowledgments}

The Population Council will like to thank government officials from Bauchi and Cross River states for their support and enabling environments that made it possible to undertake and complete this research study.

Appreciation and heartfelt thanks are extended to all supervisors, research assistants, and data collectors for their tireless efforts before, during, and after data collection for this research study.

Special thanks go to Dr. Sylvia Adebajo, the Country Director for Population Council Nigeria, as well as the HRH Project Director, Ekechi Okereke, the HRH Program Administrator for Cross River state, Godwin Unumeri, the HRH Programme Administrator for Bauchi state, Ibrahim Suleiman, and HRH Program Officer Aisha Jibril, for ensuring completion of this piece of research study. The contributions of George Eluwa, Osasuyi Dirisu, Akinwumi Akinola, and Eno-Obong Etim of Population Council Nigeria's research team for the completion of this report are also acknowledged. 


\section{List of Acronyms}

\begin{tabular}{|c|c|}
\hline AMREF & African Medical and Research Foundation \\
\hline ANC & Antenatal Care \\
\hline CHEW & Community Health Extension Worker \\
\hline $\mathrm{CHO}$ & Community Health Officer \\
\hline CHEW & Community Health Extension Worker \\
\hline CHPBN & Community Health Practitioners' Board of Nigeria \\
\hline FGD & Focus Group Discussion \\
\hline FMoH & Federal Ministry of Health \\
\hline GAC & Global Affairs Canada \\
\hline HC & Health Centre \\
\hline HP & Health Post \\
\hline HRH & Human Resources for Health \\
\hline HW & Health Worker \\
\hline IRB & Institutional Review Board \\
\hline IDI & In-Depth Interview \\
\hline JCHEW & Junior Community Health Extension Worker \\
\hline LGA & Local Government Area \\
\hline LGSC & Local Government Service Commission \\
\hline $\mathrm{MNCH}$ & Maternal, Newborn and Child Health \\
\hline MDA & Ministries, Departments, Agencies \\
\hline M\&E & Monitoring and Evaluation \\
\hline MSS & Midwives Services Scheme \\
\hline NGO & Non-Governmental Organization \\
\hline $\mathrm{NMCN}$ & Nursing and Midwifery Council of Nigeria \\
\hline NSHDP & National Strategic Health Development Plan \\
\hline PHC & Primary Health Centre/Care \\
\hline $\operatorname{scsc}$ & State Civil Service Commission \\
\hline SHMB & State Hospital Management Board \\
\hline SMoH & State Ministry of Health \\
\hline SPHCDA & State Primary Health Care Development Agency \\
\hline SPSS & Statistical Package for Social Sciences \\
\hline SURE-P & Subsidy Reinvestment and Empowerment Program \\
\hline TBA & Traditional Birth Attendant \\
\hline WDC & Ward Development Committee \\
\hline WHO & World Health Organization \\
\hline
\end{tabular}




\section{Executive Summary}

\section{Introduction}

Primary Health Care (PHC) is the first contact for care in a health care system and, at its core, is access to basic interventions that address health needs at the community level. These basic interventions are provided by key frontline health workers (FLHWs)-nurses, midwives, and community health extension workers (CHEWs)-critical for facilitating immediate access to maternal, newborn, and child health $(\mathrm{MNCH})$ services at PHC facilities. Despite the critical roles of these health worker cadres, their distribution is uneven and skewed-geographic, within levels of care and governments, in addition to poor distribution of skills-compounded by high attrition due to poor human resources for health ( $\mathrm{HRH}$ ) management and development. These factors result in gross inadequacies both among and for this critical health workforce, particularly in PHC.

Information needed to guide decision-making to address these issues is largely absent or fragmented at best, posing a major challenge to effective HRH planning and management. The aim of this study is to examine the HRH hiring, deployment, and retention procedures and practices in Cross River and Bauchi states to generate evidence to support the development of improved and gender-sensitive hiring and deployment guidelines. The study will also provide recommendations for improved HRH planning and management for better service delivery.

\section{Methodology}

The study utilized a mixed method design incorporating 43 in-depth interviews (IDIs) and 19 focus group discussions (FGDs). Overall, 781 health personnel (FLHWs, health managers, policymakers) in the two states participated in the survey. Questionnaires assessed knowledge and perspectives about HRH hiring, deployment and retention; then IDIs and FGDs explored workers' and managers' experiences and perceptions. Descriptive statistics summarized survey data and qualitative interviews that were digitally recorded, transcribed, and analyzed using NVivo 11 software. Thematic analysis explored emergent patterns and themes in the data. Ethical approval was obtained from the research ethical review committees in the two project states in addition to ethical approval from Population Council's Institutional Review Board (IRB).

\section{Findings}

Findings from this study show that although there are established policies and procedures for hiring, deployment, and retention in Bauchi and Cross River states, there is poor awareness of these policies, with gaps in implementation, and inadequate adherence to prescribed processes. Poor funding and political interference in hiring and deployment processes are the most important barriers to effective implementation identified in this study.

There is consensus that decision-making about hiring is based on identified health system needs, but with dissatisfaction with the advertising, recruiting, and orientation processes. Considerations for health worker postings include gender, workers' health conditions, security and conflict issues, family concerns, and number of years at a facility. Findings from this study also show that gender is a key consideration in health worker deployment, especially in Bauchi state, due to a preference for female midwives for antenatal care (ANC) and infant delivery.

Deployment processes are plagued by issues related to payments of rural posting allowances, family separation, staff accommodation and safety, the deplorable state of some rural health facilities, and political interference. Remuneration, delays in salary payments, staff shortages and workloads, and lack of capacity-building opportunities are major factors affecting retention. The potential for task shifting to improve service quality notwithstanding, increasing responsibilities for an overburdened workforce has serious implications for quality of care and motivation. 
Bonding practices-staff commitments to prescribed health care facilities following governmentsponsored training-exist in both states and play an important role in health worker motivation and retention. Implementation of bonding policies are, however, limited by poor compliance.

\section{Conclusion}

Challenges in retaining health workers at rural and remote areas negatively affect $\mathrm{MNCH}$ indices and PHC service delivery. The findings from this study suggest that strategies to improve HRH policy adherence are urgently needed to effectively address gaps in HRH hiring, deployment, and retention, for optimizing the quality, quantity, distribution, and skills of key FLHWs in Nigeria. 


\section{Introduction}

In Nigeria, one in every 15 children dies before reaching the age of one. ${ }^{1}$ Nigeria has one of the highest maternal mortality ratios in the world and contributes the largest proportion of stillbirths and pregnancy-related, postpartum, and neonatal deaths by any country. ${ }^{2}$ The proportions of these deaths differ considerably across many parts of Nigeria, but are generally higher in northern Nigeria. Health system challenges such as access, poor attitudes of personnel, lack of skilled birth attendants, and a preference for home births conducted by self, family members, or traditional birth attendants (TBAs), are key factors that are reinforced by cultural beliefs. ${ }^{3}$ Efficient delivery of maternal, newborn, and child health $(\mathrm{MNCH})$ services and delivery of high quality health care services to improve patient health outcomes both hinge on the availability of skilled health workers, which is dependent upon effective human resources for health $(\mathrm{HRH})$ management.

There is insufficient availability of skilled health workers in Nigeria due not only to shortages but inequitable distribution of appropriate health workforce cadres in favor of urban areas. ${ }^{4}$ Nigeria's Federal Ministry of Health (FMoH) developed a comprehensive National HRH Policy (2006) as well as national HRH strategic plans (2008-2012, 2009-2015) to guide HRH policy and response with renewed focus on comprehensive and integrated HRH management.5,6 The framework of the National Strategic Health Development Plan (NSHDP, 2010-2015) provided a better coordinated health sector response to HRH needs such as availability and equitable distribution of a skilled and well-motivated health workforce. ${ }^{6}$ State governments were expected to adapt and use this $\mathrm{HRH}$ policy and strategic plans for HRH planning and management. By the end of 2015, however, only 15 states (out of 36 ) had adopted the policy, none of the country's 774 local government areas (LGAs) had strategic HRH plans, with no policy translation to action at any level. ${ }^{7}$

Weak capacity for policy dialogue and complex coordination structures contributed to policy adoption and implementation failures. ${ }^{7}$ Inequitable distribution of training institutions as well as trained health workers, combined with high attrition due to poor HRH management and development, are significant factors. ${ }^{8}$ Poor links between human resources needs and production have resulted in gross inadequacies in the critical health workforce, particularly for primary health care $(\mathrm{PHC}) .9,10 \mathrm{HRH}$ data and information for decision-making are largely absent, or fragmented at best, posing a major challenge to effective HRH planning and management. ${ }^{7}$

The federal government implemented some initiatives to address PHC HRH availability. ${ }^{11}$ The 2010 midwives' services scheme (MSS) led to the recruitment and deployment of about 4,007 midwives to rural PHC facilities across Nigeria. 8,12 The MSS scheme best demonstrates the dynamics of HRH hiring, deployment, and retention in Nigeria: The program increased the midwife coverage in rural areas, but its recruitment and deployment processes were not informed by HRH mapping or workload analysis. Problems such as unreliable salary payments and insufficient infrastructure maintenance by both states and local government areas (LGAs) led many midwives to leave the scheme. ${ }^{12}$ Findings from a study in three northern Nigerian states show that most midwives were dissatisfied due to lack of career growth opportunities, personal safety concerns, accommodation challenges, in addition to poor welfare packages. ${ }^{13}$ These challenges resulted in about 38 percent attrition within two years. ${ }^{13}$ In 2012, the Subsidy Reinvestment and Empowerment Maternal and Child Health Programme (SURE-P) was introduced by the federal government to both replace and build upon MSS's efforts in addressing the country's poor MNCH indices. SURE-P's HRH component involved recruiting, training, and deploying midwives to selected PHC and secondary health facilities. ${ }^{14}$ Due to issues similar to the MSS program, however, the project ended abruptly in 2015. ${ }^{15}$

To deal effectively with Nigeria's HRH issues, there is a need to develop strategies that effectively address the processes of hiring, deployment, and retention at all levels, national and sub-national. This study, in Cross River and Bauchi states, was undertaken for an in-depth understanding of the $\mathrm{HRH}$ situation and current practices of hiring, deployment, and retention in these two states. 
This in-depth assessment will enable Population Council and the HRH project to make contextually appropriate recommendations for $\mathrm{HRH}$ planning and management that can improve the availability, distribution, and retention of the critical frontline health workforce in these states.

\section{Justification for the Study}

Frontline health workers (FLHWs) are critical for facilitating access to $\mathrm{MNCH}$ services in rural and remote areas. Efficient delivery of $\mathrm{MNCH}$ services depends on the availability of skilled FLHWs. This is, unfortunately, not the case in Nigeria due to an inequitable distribution and shortage of appropriate cadres of health workers. ${ }^{4}$ Strategies to effectively address gaps in HRH hiring, deployment, and retention, at national and state levels, are needed to optimize FLHWs-their quality, quantity, distribution, and skills-in Nigeria. Little is known about the documentation and implementation of policies and processes for FLHW hiring, deployment, and retention, and important contextual factors, particularly in Cross River and Bauchi, are poorly understood. This study will enable the Enhancing the Ability of Frontline Health Workers to Improve Health in Nigeria project to make contextually appropriate recommendations for $\mathrm{HRH}$ planning and management to improve critical FLHW availability, distribution, and retention in these states. The findings from this assessment report will be used to develop improved gender-sensitive hiring and deployment guidelines, for HRH project states.

\section{Aims and Objectives of the Study}

\section{Aim of the Study}

The aim of this study is to examine the HRH hiring, deployment, and retention procedures and practices in Cross River and Bauchi to generate evidence for improved and gender-sensitive hiring and deployment guidelines. The study will also provide recommendations for improved HRH planning and management, for better service delivery.

\section{Specific Objectives}

- Describe the HRH situation in both states: FLHW quantity, quality, distribution and retention;

- Determine extant policies, strategies, plans, and procedures for HRH planning and management, and how they influence:

- Hiring of a critical health workforce

- Deployment to ensure equitable distribution, and

- Retention, in terms of geography (urban versus rural), level of care (primary, secondary), level of government (state, LGA), and type of facility;

- Identify and examine contextual factors that enable or constrain adoption and implementation of existing national policies and strategies, for $\mathrm{HRH}$ planning and management by state and local governments; and

- Make recommendations for improved HRH hiring, deployment, and retention procedures, for better quality of health service delivery

\section{Research Questions}

1. What is the HRH situation in terms of hiring, quantity, distribution, and retention in Cross River and Bauchi? 
2. What policies, plans, or strategies exist in both states, for HRH planning and management, especially for FLHW hiring, deployment, and retention? In what ways are they being implemented at state and LGA levels?

3. How do contextual factors determine adoption and implementation of existing national policies for HRH planning and management, by state and local governments? 


\section{Methods}

\section{Study Site}

The study was conducted in Bauchi (NorthEast) and Cross River (South-South) states (Figure 1) of Nigeria. Both states were selected for study because they are $\mathrm{HRH}$ project focal states, and contrasting their data, as they are geographically and culturally different, but with mutually poor $\mathrm{HRH}$ situations and indices, will be useful.

\section{Study Design and Study Population}

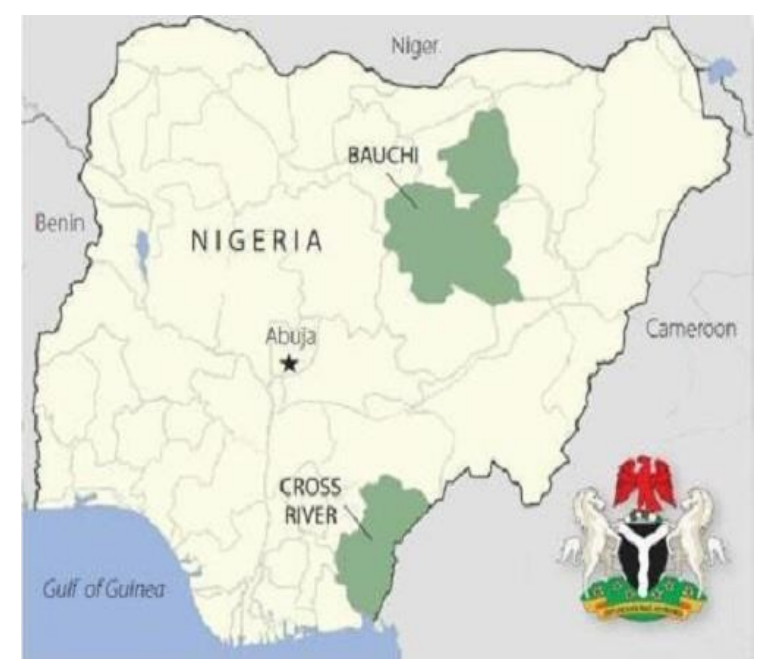

Figure 1: Study Locations

This assessment utilized a cross-sectional, mixed-methods study design comprising a document review, in-depth interviews (IDIs), focus group discussions (FGDs), and survey. The mixedmethods design included descriptive, exploratory, and convergent models.

The key study population include:

1. FLHWs-Nurses, Midwives and Community Health Workers i.e. Community Health Officers (CHOs), Community Health Extension Workers (CHEWs) and Junior Community Health Extension Workers (JCHEWs)-working at health posts, PHC clinics, and comprehensive health care centres (CHCs)

2. Officers-in-charge of PHC facilities, and Health managers, and

3. Policymakers in ministries, departments, and agencies (MDAs).

\section{Sample Size}

\section{Quantitative Survey of Health Workers and Managers}

Seven hundred eighty-one (781) survey participants were enrolled in the two states for the study.

Table 1: Survey participants in Bauchi and Cross River states

\begin{tabular}{|l|c|c|c|}
\hline \multicolumn{1}{|c|}{ Participants } & Bauchi & Cross River & Total \\
\hline Officers in-Charge of PHC facilities* & 114 & 75 & 189 \\
\hline Policy Makers* & 9 & 37 & 46 \\
\hline Frontline Health Workers & 281 & 265 & 546 \\
\hline TOTAL & 404 & 377 & 781 \\
\hline
\end{tabular}

*Officers in-charge and Policymakers constitute Health Managers

\section{Sample size determination}

The minimum sample size of survey participants to be recruited in both states was estimated to be 340 for each state (total of 680 participants). The minimum sample size was calculated using Leslie Kish's formula. ${ }^{16}$ We also assumed a satisfaction rate of 32.9 percent based on previous work by Ayamolowo et al., 17 where the proportion of health managers satisfied with work conditions was 32.9 percent. The minimum sample size in each state was obtained as follows:

$$
n=\quad\left(\llbracket Z(1-\propto / 2) \rrbracket^{\wedge} 2^{*} p(1-p)\right) / d^{\wedge} 2
$$

Where,

$$
\mathrm{n}=\quad \text { minimum sample size per state }
$$


$\mathrm{Z} 1-\alpha / 2=$ Standard normal deviate at $5 \%$ type 1 error (i.e. $p<0.05$ ) is 1.96

$\mathrm{p}=\quad$ expected proportion in population taken as $32.9 \%$

$d=\quad$ absolute error or precision taken as $5 \%$.

To increase robustness and account for non-responses, the actual number of FLHWs and health care managers enrolled to participate in the survey were as follows:

\section{FLHW survey}

A total of 546 FLHWs (CHEWs, JCHEWs, CHOs, nurses, midwives) in selected facilities were enrolled, with inclusion criteria "female or male health worker...working in the selected PHC facility in the last 12 months...providing $\mathrm{MNCH}$ services in the selected PHC facility and consenting to participate." Exclusion criteria were "FLHWs on leave or who have travelled out of the LGAs, or unavailable during the study period, or did not consent to participate."

\section{Health manager and policymaker survey}

A total of 235 Health managers, with 46 policymakers (MDA stakeholders) and 189 officers in charge of health facilities were recruited from the two states.

\section{Qualitative inquiry of stakeholders}

\section{In-depth Interviews}

A total of 43 IDIs with stakeholders-21 and 22, respectively, in Bauchi and Cross River-included PHC officers in-charge, FLHWs, and the directors of each state's Ministry of Health (SMoH), Civil Service Commission, Local Government Service Commission, PHC Department, PHC Development Agency (SPHCDA), and Medical Services, in addition to the directors of personnel for local government areas (LGAs) and LGA PHC coordinators. Officials from the National PHC Development Agency (NPHCDA), the National Association of Nurses and Midwives, National Association of Community Health Practitioners of Nigeria (NACHPN), Hospital Management Board, and Community Health Practitioners Registration Board were also interviewed.

\section{Focus Group Discussions}

A total of 19 FGDs, nine in Cross River and 10 in Bauchi, included FLHWs, facility In-charges, $\mathrm{HRH}$ focal persons from each LGAs, and officials from each SPHCDA, SMoH and Civil Service Commission, as well as NACHPN, Nursing and Midwifery colleges, and Medical and Health Workers Union.

\section{Sampling Procedure}

\section{Stage One: Selection of focal LGAs}

Both Bauchi and Cross River have three senatorial districts. For each state, the list of LGAs in each senatorial district was generated and classified as urban or rural. One urban and one rural LGA was randomly selected from each senatorial district.

Table 2: Local government areas selected from Bauchi and Cross River senatorial zones

\begin{tabular}{|c|c|c|c|c|c|}
\hline \multicolumn{3}{|c|}{ Bauchi State } & \multicolumn{3}{|c|}{ Cross River State } \\
\hline LGA & Rural/Urban & Senatorial District & LGA & Rural/ Urban & Senatorial District \\
\hline Bauchi & Urban & \multirow[t]{2}{*}{ South } & $\begin{array}{l}\text { Calabar } \\
\text { Municipal }\end{array}$ & Urban & \multirow[t]{2}{*}{ South } \\
\hline Alkaleri & Rural & & Odukpani & Rural & \\
\hline Ganjuwa & Urban & \multirow{2}{*}{ Central } & Ikom & Urban & \multirow{2}{*}{ Central } \\
\hline Darazo & Rural & & Etung & Rural & \\
\hline Katagum & Urban & \multirow{2}{*}{ North } & Obudu & Urban & \multirow{2}{*}{ North } \\
\hline Giade & Rural & & Obanliku & Rural & \\
\hline
\end{tabular}




\section{Stage Two: Selection of facilities and recruitment of health workers}

In each of the 12 LGAs, facilities visited were selected randomly from the facility lists with the LGA PHC Coordinator. All facility-in-charges and FLHWs of the cadres of interest, i.e. nurses, midwives, CHOs, CHEWs, and JCHEWs, available at the facilities visited were interviewed.

\section{Development of Instruments: Interview Guides and Survey Questionnaires}

The tools for this study were developed based on the study objectives and expected outcomes. Some portions of the questionnaire for FLHWs and Health Managers were adapted from a study on 'Factors Affecting Motivation and Retention of Primary Level Health Care Workers in Three Disparate Regions in Kenya', conducted by AMREF (2012). ${ }^{18}$ IDI and FGD guides were developed to capture the knowledge, perceptions and experiences of health managers and health workers on hiring, deployment, and retention of health workers in each state. Details of the study instruments and the variables are outlined in the table below:

Table 3: Study Instruments, Participants and Issues Addressed in Each Instrument

\begin{tabular}{|c|c|c|c|}
\hline Type of Instrument & $\begin{array}{l}\text { Study } \\
\text { Design }\end{array}$ & $\begin{array}{c}\text { Type } \\
\text { of Respondent }\end{array}$ & Issues Addressed \\
\hline $\begin{array}{l}\text { Facility } \\
\text { Managers/ } \\
\text { Policymakers } \\
\text { Questionnaire }\end{array}$ & Quantitative & $\begin{array}{l}\text { Facility heads } \\
\text { or officers } \\
\text { in-charge }\end{array}$ & $\begin{array}{c}\text { Section A: } \begin{array}{l}\text { Socio-demographic } \\
\text { characteristics, background }\end{array} \\
\text { Section B: } \begin{array}{l}\text { Individual characteristics } \\
\text { Section C: }\end{array} \\
\begin{array}{l}\text { HRH hiring and deployment } \\
\text { policies and procedures }\end{array} \\
\text { Section D: } \begin{array}{l}\text { HRH retention policies and } \\
\text { procedures }\end{array} \\
\text { Section E: Additional questions for facility } \\
\text { managers (work environment } \\
\text { at facility) }\end{array}$ \\
\hline $\begin{array}{l}\text { Frontline } \\
\text { Health Workers } \\
\text { (FLHW) } \\
\text { Questionnaire }\end{array}$ & Quantitative & $\begin{array}{l}\text { FLHWs } \\
\text { (nurses, } \\
\text { midwives, } \\
\text { nurse- } \\
\text { midwives, } \\
\text { CHOs, CHEWs, } \\
\text { JCHEWs }\end{array}$ & $\begin{array}{l}\text { Section 1: Socio-demographic } \\
\text { Characteristics, Background } \\
\text { Section 2: Individual Characteristics } \\
\text { Section 3: HRH Hiring } \\
\text { Section 4: HRH Deployment } \\
\text { Section 5: HRH Retention }\end{array}$ \\
\hline $\begin{array}{l}\text { In depth Interview } \\
\text { guide }\end{array}$ & Qualitative & $\begin{array}{l}\text { Health } \\
\text { managers, } \\
\text { policymakers, } \\
\text { officers } \\
\text { in-charge } \\
\text { or facility } \\
\text { heads }\end{array}$ & $\begin{array}{l}\text { Experience and perception of policies, } \\
\text { processes, and practices for hiring, } \\
\text { deployment, and retention in Bauchi } \\
\text { and Cross River states }\end{array}$ \\
\hline $\begin{array}{l}\text { Focus Group } \\
\text { Discussion guide }\end{array}$ & Qualitative & $\begin{array}{l}\text { FLHWs, } \\
\text { Health } \\
\text { Managers, } \\
\text { policymakers, } \\
\text { officers-in } \\
\text { charge } \\
\text { or facility } \\
\text { heads }\end{array}$ & $\begin{array}{l}\text { Experience and perception of policies, } \\
\text { processes, and practices for hiring, } \\
\text { deployment, and retention in Bauchi } \\
\text { and Cross River states }\end{array}$ \\
\hline
\end{tabular}




\section{Preparation for Data Collection}

\section{Instrument Validation}

Instruments were developed in English. Electronic data collection, using personal digital assistants, were employed to administer the survey. Questionnaires were pre-tested. The qualitative guides were also pilot-tested.

\section{Field Work}

Twelve HRH focal persons (with familiarity with the subject matter and context) in each state were trained on survey questionnaire use, research ethics, and electronic data collection, from June $4^{\text {th }}$ through $8^{\text {th }}$ in Cross River, and June $2^{\text {nd }}$ through $6^{\text {th }}$ in Bauchi. Survey interviews were conducted from June $11^{\text {th }}$ to $16^{\text {th }}$ in Cross River and June $9^{\text {th }}$ to $14^{\text {th }}$ in Bauchi. In each state, a team of four data collectors and one supervisor were deployed in each senatorial district. $\mathrm{HRH}$ focal persons were posted to LGAs outside their place of duty to reduce bias.

Each study team, on arrival at their assigned LGAs, paid a courtesy visit to the PHC Coordinator, who had been informed of the study. In consultation with the PHC departments in each LGA, a facility list (based on ward distribution), list of available personnel, disaggregated by cadre, and other relevant documents were provided. Each study team was provided with a "mobilizer" who served as a guide to the selected health facilities. At each facility visited, the officer-in-charge was administered the manager questionnaire, while other FLHWs were administered the FLHW survey questionnaire. Survey data were collected on android tablets and reviewed daily by supervisors before they were uploaded to the electronic database specifically designed for the study.

\section{Data Quality Control}

Data quality was ensured by building in buffer questions to the questionnaires, programming skip patterns, and limiting characters and figures for numerical data. Supervisors performed spot checks on completed questionnaires and verified collected data daily before data were uploaded to the electronic database.

Table 4: Overview of the number of FLHWs interviewed within study LGAs

\begin{tabular}{|c|c|c|c|c|c|c|}
\hline \multicolumn{7}{|c|}{ Bauchi } \\
\hline \multirow{2}{*}{ LGA } & \multicolumn{5}{|c|}{ Number of FLHWs recruited, by type of PHC Facility } & \multirow{2}{*}{ Total } \\
\hline & PHC Centre & Health Centre & Health Post & Health Clinic & Dispensary & \\
\hline Bauchi & 79 & 6 & 0 & 3 & 1 & 89 \\
\hline Katagum & 25 & 10 & 0 & 0 & 0 & 35 \\
\hline Giade & 17 & 5 & 0 & 3 & 0 & 25 \\
\hline Ganjuwa & 33 & 6 & 7 & 9 & 3 & 58 \\
\hline Darazo & 14 & 2 & 1 & 12 & 2 & 31 \\
\hline Alkaleri & 34 & 2 & 0 & 5 & 2 & 43 \\
\hline Total & 202 & 31 & 8 & 32 & 8 & 281 \\
\hline \multicolumn{7}{|c|}{ Cross River } \\
\hline \multirow{2}{*}{ LGA } & \multicolumn{5}{|c|}{ Number of FLHWs recruited, by type of PHC Facility } & \multirow{2}{*}{ Total } \\
\hline & $\mathrm{CHC}$ & PHC Centre & Health Centre & \multicolumn{2}{|c|}{ Health Post } & \\
\hline Obudu & 0 & 27 & $\begin{array}{l}0 \\
\end{array}$ & \multicolumn{2}{|c|}{31} & 58 \\
\hline Obanliku & 5 & 11 & 8 & \multicolumn{2}{|c|}{7} & 31 \\
\hline Ikom & 12 & 18 & 2 & \multicolumn{2}{|c|}{22} & 54 \\
\hline Etung & 0 & 26 & 1 & \multicolumn{2}{|c|}{10} & 37 \\
\hline Calabar (city) & 0 & 29 & 21 & \multicolumn{2}{|c|}{9} & 59 \\
\hline Odukpani & 0 & 12 & 7 & \multicolumn{2}{|c|}{7} & 26 \\
\hline Total & 17 & 123 & 39 & \multicolumn{2}{|c|}{86} & 265 \\
\hline
\end{tabular}




\section{Data Processing and Analysis}

\section{Quantitative and Qualitative Analytical Framework}

\section{Quantitative}

Descriptive statistics summarized the data and results using frequency tables, percentages, and means.

\section{Categorizations and variable computing \\ FLHWs}

Age was categorized into three classes ( 0 to 34 years, 35 to 44 years, 45 years and older). Given that the expected minimum work hours recognized by Nigerian labor is 40 hours per week, we categorized "hours worked weekly" into four groups (<40 hours, 40 hours, 41 to 50 hours, $>50$ hours). A 'shift' in this study was described as how many times a worker changes from 'on duty' to not, and vice versa. "Number of shifts in the past 30 days" was categorized into four groups (no shift, 1 to 2 shifts, 3 shifts, $>3$ shifts). Similarly, number of outreaches was categorized by three (no outreach, 1 to 2 outreaches, 3 outreaches or more). Number of patients attended weekly at the health facility was categorized by three ( 0 to 49,50 to 149,150 patients or more) as well, while number of patients personally seen by a FLHW in the past seven days was categorized into three (0 to 20,21 to 40,41 patients or more).

To understand the relative workload of each health worker at his or her health facility, we calculated workload fraction as [number of patients personally seen by HW weekly in HF/number of patients attended weekly in the HF] $\times 100$. Output of this workload fraction was dichotomized $(<50 \%, 50 \%$ or more). Monthly income was categorized into four groups ( $<50,000$ Naira, 50,000 to 100,000 Naira, 101,000 to 50,000 Naira, 151,000 Naira and more)

\section{Health Managers}

The ages of health managers was categorized into three ( $<35$ years, 35 to 44 years, 45 years and older). Length of work in organization was reported as Mean (S.D).

To evaluate managers' perceptions of the importance of work satisfaction factors to their staff, and the performance of their facility related to these factors, only "Very Important" was reported for importance since other options, i.e. "Somewhat Important" and "Not Important", had scant results. For performance, only "We Perform Very Well" was reported because other options, i.e. "We Perform Adequately" and "We Don't Perform Well" were scant as well.

\section{Qualitative}

Interviews were recorded digitally, transcribed verbatim, and transferred to NVivo 11 software for analysis. The analytical strategy was thematic, used to explore emergent patterns and themes in the data. The research team reviewed the data and developed a thematic framework of codes through consensus.

\section{Ethical Considerations}

Ethical approval was granted by the Bauchi State Research Ethical Committee, Cross River State Research Ethical Committee, and Population Council's Institutional Review Board (IRB) in New York. In addition, permission was sought from state and LGA officials and community leaders, after a courtesy visit explaining the study, its objectives, and procedures. The study was conducted according to ethical guidelines and principles of confidentiality, beneficence, and voluntariness. Informed consent was obtained from each respondent prior to commencing interviews for the study. 


\section{Results}

\section{Quantitative Findings}

\section{Frontline Health Workers}

\section{Socio-demographic and Background Characteristics}

FLHW respondents in Bauchi were, on average, younger (mean age 36) than in Cross River (mean age 42). Respondents younger than 35 constituted the largest group (47\%) in Bauchi, while those 45 or older were greatest (42\%) in Cross River. Most survey respondents were female (Bauchi $52 \%$, Cross River 89\%), married (Bauchi 94\%, Cross River 74\%), and had children (Bauchi 92\%, Cross River 91\%). While most Bauchi respondents were Muslim (88\%), all respondents from Cross River were Christian (100\%). Over one third of respondents in both states (Bauchi 38\%, Cross River 39\%) had a school certificate for highest educational qualification, while 53 percent and 38 percent of respondents reported a higher diploma in Bauchi and Cross River, respectively. JCHEWs constituted the largest cadre of FLHWs interviewed (Bauchi 50\%, Cross River 60\%). Most respondents (Bauchi 62\%, Cross River 67\%) reported that their health facility income accounted for their family's entire income.

Table 5: Socio-demographic characteristics of health workers

\begin{tabular}{|c|c|c|}
\hline Characteristic & $\begin{array}{c}\text { Bauchi }(n=281) \\
n(\%)\end{array}$ & $\begin{array}{c}\text { Cross River }(n=265) \\
n(\%)\end{array}$ \\
\hline Mean (years) & 36 & 42 \\
\hline$<35$ years & $132(47.0)$ & $61(23.0)$ \\
\hline 35 to 44 years & $98(34.9)$ & $92(34.7)$ \\
\hline 45 years and older & $51(18.1)$ & $112(42.3)$ \\
\hline \multicolumn{3}{|l|}{ Gender } \\
\hline Male & $135(48.0)$ & $30(11.3)$ \\
\hline Female & $146(52.0)$ & $235(88.7)$ \\
\hline \multicolumn{3}{|l|}{ Marital Status } \\
\hline Single & $15(5.3)$ & $52(19.6)$ \\
\hline Married & $264(94.0)$ & $196(74.0)$ \\
\hline Separated/Divorced/Widowed & $2(0.7)$ & $17(6.4)$ \\
\hline \multicolumn{3}{|l|}{ Religion } \\
\hline Christian & $34(12.1)$ & $265(100)$ \\
\hline Muslim & 247 (87.9) & $0(0.0)$ \\
\hline \multicolumn{3}{|l|}{ Children? } \\
\hline Yes & $259(92.2)$ & $242(91.3)$ \\
\hline No & $22(7.8)$ & $23(8.7)$ \\
\hline \multicolumn{3}{|l|}{ Highest Education or Qualification } \\
\hline Certificate & $108(38.4)$ & 104 (39.2) \\
\hline Diploma & $149(53.0)$ & $101(38.1)$ \\
\hline Higher Diploma & $9(3.2)$ & $35(13.2)$ \\
\hline Nurse & $5(1.8)$ & - \\
\hline Nurse and Midwife & $10(3.6)$ & $6(2.3)$ \\
\hline University (B.Sc) & - & $16(6.0)$ \\
\hline Masters' degree & - & $3(1.1)$ \\
\hline \multicolumn{3}{|l|}{ Professional Cadre } \\
\hline JCHEW & 110 (39.1) & $45(17.0)$ \\
\hline CHEW & $140(49.8)$ & $158(59.6)$ \\
\hline $\mathrm{CHO}$ & $6(2.1)$ & $51(19.2)$ \\
\hline Nurse & $12(4.3)$ & $3(1.1)$ \\
\hline Midwife & $13(4.6)$ & $8(3.0)$ \\
\hline \multicolumn{3}{|l|}{ Salary Proportion of Total Family Income } \\
\hline Only Income & $175(62.3)$ & $178(67.2)$ \\
\hline Partial Contribution to household income $(<50 \%)$ & $59(21.0)$ & $56(21.1)$ \\
\hline Major Contribution to household income (>50\%) & $47(16.7)$ & $31(11.7)$ \\
\hline Experience as Health Care Provider (mean, years) & 11 & 14 \\
\hline
\end{tabular}




\section{Hiring of Health Workers}

\section{Vacancy and advertisement practices and procedures}

Fifty-two percent (52\%) of respondents in Bauchi and the majority (90\%) in Cross River reported that their positions were advertised prior to their recruitment. Only a small proportion of respondents in both states did not know whether vacancies were advertised (Bauchi 7\%, Cross River $4 \%$ ). Of those who reported the position advertisement, the majority reported seeing it (Bauchi 75\%, Cross River 62\%). The most prevalent means of advertisement were radio (Bauchi $52 \%$, Cross River $48 \%$ ) and word-of-mouth (Bauchi 55\%, Cross River 42\%), followed by television (Bauchi 17\%, Cross River $8 \%$ ). The common contents of vacancy advertisements were: cadre of health worker (Bauchi $64 \%$, Cross River 86\%), number of vacancies (Bauchi 50\%, Cross River $60 \%$ ), and specific facility where vacancies existed (Bauchi 13\%, Cross River 29\%). Only a few in Bauchi (4\%) reported content that included job specifications, skill sets, and attributes, while more than half $(58 \%)$ in Cross River reported those elements. In both states the most common means of job application is hard copy (typed or handwritten) application (Bauchi 87\%, Cross River 71\%). A small proportion of health workers never completed any application before their employment, in both states (Bauchi 10\%, Cross River 4\%).

Table 6: Vacancy and advertisement practices and procedures

\begin{tabular}{|l|c|c|}
\hline Characteristic & $\begin{array}{c}\text { Bauchi } \\
\mathrm{n}(\%)\end{array}$ & $\begin{array}{c}\text { Cross River } \\
\mathrm{n}(\%)\end{array}$ \\
\hline Was job vacancy advertised before recruitment & $\mathrm{n}=281$ & $\mathrm{n}=265$ \\
\hline Yes & $144(52.1)$ & $241(90.9)$ \\
\hline No & $117(41.6)$ & $14(5.3)$ \\
\hline Don't know & $20(7.1)$ & $10(3.8)$ \\
\hline Did you see advert? & $\mathrm{n}=144$ & $\mathrm{n}=241$ \\
\hline Yes & $109(75.7)$ & $149(61.8)$ \\
\hline No & $35(24.3)$ & $92(38.2)$ \\
\hline Channel of advert & $\mathrm{n}=109$ & $\mathrm{n}=149$ \\
\hline Daily Newspaper & $3(1.1)$ & $9(3.2)$ \\
\hline Online/internet jobsites & $2(1.8)$ & $2(1.3)$ \\
\hline Radio & $57(52.3)$ & $72(48.3)$ \\
\hline Television & $19(17.4)$ & $12(8.1)$ \\
\hline Church/mosque announcement & $0(0.0)$ & $11(7.4)$ \\
\hline Word of mouth & $60(55.0)$ & $62(41.6)$ \\
\hline Content of advert & $(\mathrm{n}=109)$ & $(\mathrm{n}=149)$ \\
\hline Number of vacancies & $55(50.5)$ & $90(60.4)$ \\
\hline Specific health facility where vacancy exists & $14(12.8)$ & $43(28.9)$ \\
\hline LGA where vacancy exists & $36(33.0)$ & $39(26.2)$ \\
\hline Cadre of health worker required & $70(64.2)$ & $128(85.9)$ \\
\hline Purpose and job role & $9(8.3)$ & $44(29.5)$ \\
\hline Job specifications, qualifications, personal attributes, skill sets & $11(3.9)$ & $87(58.4)$ \\
\hline Salary/Remuneration & $0(0.0)$ & $15(10.1)$ \\
\hline Mode of application & $(\mathrm{n}=281)$ & $(\mathrm{n}=265)$ \\
\hline Online & $0(0.0)$ & $1(0.4)$ \\
\hline Hard copy (typed-handwritten) & $245(87.2)$ & $189(71.3)$ \\
\hline No written application & $29(10.3)$ & $11(4.2)$ \\
\hline Others & $9(3.2)$ & $74(27.9)$ \\
\hline
\end{tabular}

\section{Hiring interview procedures}

In both states, most (Bauchi $86 \%$, Cross River 97\%) survey respondents had been formally interviewed prior to selection for their current job. In Bauchi, 77 percent, 12 percent, and eight percent, respectively, had been notified via 'word-of-mouth', noticeboard, and text messages; in Cross River, 33 percent, 83 percent, and 96 percent had been were notified via 'word-of-mouth', noticeboard, and text message, respectively. A higher proportion of Bauchi respondents were notified by word-of-mouth than in Cross River, where noticeboards were primarily used. 
The majority of those interviewed in Cross River (95\%), and slightly over half in Bauchi (57\%), believe lists of shortlisted candidates were published publicly. In both states, most (Bauchi 71\%, Cross River $82 \%$ ) of those interviewed attended a panel interview. One-on-one interviews are uncommon in both states, but utilized more in Bauchi (17\%) than in Cross River (5\%). In both states, almost all of those interviewed (Bauchi 99\%, Cross River 100\%) presented relevant documents during the interview, primarily education certificates (Bauchi 91\%, Cross River 98\%), along with professional certificates (Bauchi 62\%, Cross River 53\%), and practice licences (Bauchi $26 \%$, Cross River $34 \%$ ). In both states, a clear majority believe they were recruited based upon merit (Bauchi 81\%, Cross River 91\%). Although the majority reported merit as the greatest factor in their hiring (Bauchi 79\%, Cross River 85\%), a small proportion (Bauchi 8\%, Cross River 2\%) still consider a personal relationship with a decision-maker in government as the greatest factor.

Table 7: Interview practices and procedures

\begin{tabular}{|l|c|c|}
\hline Characteristic & $\begin{array}{c}\text { Bauchi } \\
\mathrm{n}(\%)\end{array}$ & $\begin{array}{c}\text { Cross River } \\
\mathrm{n}(\%)\end{array}$ \\
\hline Were you interviewed before selected for this job? & $\mathrm{n}=281$ & $\mathrm{n}=265$ \\
\hline Yes & $242(86.1)$ & $256(96.6)$ \\
\hline No & $39(13.9)$ & $9(3.4)$ \\
\hline Mode of notification for interview & $\mathrm{n}=242$ & $\mathrm{n}=256$ \\
\hline Pasted on Noticeboard & $28(11.6)$ & $213(83.2)$ \\
\hline I was sent a text message & $20(8.3)$ & $8(96.9)$ \\
\hline I received an invitation letter & $34(14.0)$ & $15(5.9)$ \\
\hline Word-of-mouth & $186(76.9)$ & $84(32.8)$ \\
\hline Was shortlisted candidate list published publicly? & $\mathrm{n}=242$ & $\mathrm{n}=256$ \\
\hline Yes & $138(57.0)$ & $244(95.3)$ \\
\hline No & $67(23.8)$ & $3(1.2)$ \\
\hline Don't know & $37(13.2)$ & $9(3.5)$ \\
\hline Type of interview & $\mathrm{n}=242$ & $\mathrm{n}=256$ \\
\hline Panel interview & $171(70.7)$ & $211(82.4)$ \\
\hline Individual interview/one-on-one & $41(16.9)$ & $13(5.1)$ \\
\hline Both one-on-one and panel interview & $30(12.4)$ & $32(12.5)$ \\
\hline Presented documents during interview? & $\mathrm{n}=205$ & $\mathrm{n}=247$ \\
\hline Yes & $203(99.0)$ & $247(100.0)$ \\
\hline No & $2(1.0)$ & $0(0.0)$ \\
\hline Type of documents presented during interview & $\mathrm{n}=223$ & $\mathrm{n}=247$ \\
\hline Education certificates & $184(90.6)$ & $242(98.0)$ \\
\hline Professional certificates & $126(62.1)$ & $131(53.0)$ \\
\hline Practicing license & $52(25.6)$ & $85(34.4)$ \\
\hline ID Card & $6(3.0)$ & $14(5.7)$ \\
\hline Others & $20(9.9)$ & $17(6.9)$ \\
\hline Were you asked questions on competence and knowledge? & $\mathrm{n}=205$ & $\mathrm{n}=247$ \\
\hline Yes & $197(96.1)$ & $233(94.3)$ \\
\hline No & $8(3.9)$ & $14(5.7)$ \\
\hline Would you say you were recruited to current job based on merit? & $\mathrm{N}=281$ & $\mathrm{n}=265$ \\
\hline Yes & $228(81.1)$ & $242(91.3)$ \\
\hline No & $6(2.1)$ & $6(2.3)$ \\
\hline Not sure & $47(16.7)$ & $17(6.4)$ \\
\hline Greatest factor in your hiring & $\mathrm{n}=281$ & $\mathrm{n}=265$ \\
\hline Merit & $221(78.6)$ & $225(84.9)$ \\
\hline Quota system & $38(13.5)$ & $34(12.8)$ \\
\hline Personal relationship with decision maker in government & $22(7.8)$ & $6(2.3)$ \\
\hline & & \\
\hline & & \\
\hline
\end{tabular}

Induction, orientation and documentation procedures

Almost all FLHW respondents in both states were issued employment letters (Bauchi 99\%, Cross River 98\%). More than half of respondents in each state received an offer letter no later than one month after final interview (Bauchi 61\%, Cross River 53\%). In both states less than one third of respondents (Bauchi 28\%, Cross River 30\%) had their temporary positions converted to full 
employment within two years. ${ }^{\text {a }}$ In Bauchi, slightly over half (57\%) of respondents were provided with an orientation, while about three quarters $(77 \%)$ in Cross River were. About one third $(36 \%)$ of Bauchi respondents were provided with a clear job description, while over half (55\%) in Cross River were. In both states, most health workers were not provided with a staff manual (Bauchi $83 \%$, Cross River $74 \%$ ).

Almost all health workers were requested to document their credentials after hiring (Bauchi 98\%, Cross River 98\%), most were linked to a supervisor (Bauchi $72 \%$, Cross River $72 \%$ ), but not bonded $^{\mathrm{b}}$ (Bauchi $88 \%$, Cross River $62 \%$ ). For those who were bonded, the mean (SD) durations were 3.03 (0.63) and 3.8 (1.33) years in Bauchi and Cross River, respectively. In both states, most health workers graduated from government health training institutions (HTIs) (Bauchi 94\%, Cross River 83\%).

Table 8: Induction, orientation and documentation procedures

\begin{tabular}{|c|c|c|}
\hline Characteristic & $\begin{array}{c}\text { Bauchi } \\
\text { n (\%) }\end{array}$ & $\begin{array}{c}\text { Cross River } \\
\mathrm{n}(\%)\end{array}$ \\
\hline Provided employment letter & $\mathrm{n}=\mathbf{2 8 1}$ & $n=265$ \\
\hline Yes & $278(98.9)$ & $259(97.7)$ \\
\hline No & $3(1.1)$ & $6(2.3)$ \\
\hline How long after last interview were you given an offer letter? & $n=278$ & $n=259$ \\
\hline Immediately & $85(30.6)$ & $66(25.5)$ \\
\hline less than 1 month & $86(30.9)$ & $71(27.4)$ \\
\hline 2 to 3 months & $70(25.2)$ & $64(24.7)$ \\
\hline 4 months or later & 37 (13.3) & $58(22.4)$ \\
\hline Time before appointment was confirmed as employment & $\mathrm{n}=\mathbf{2 7 8}$ & $\mathrm{n}=\mathbf{2 5 9}$ \\
\hline$<1$ year & $25(9.0)$ & $18(6.9)$ \\
\hline 1 year & $21(7.6)$ & $4(1.5)$ \\
\hline$>1$ year $<2$ years & $31(11.2)$ & $55(21.2)$ \\
\hline$>2$ years $<3$ years & $51(18.3)$ & $136(52.5)$ \\
\hline 3 years & $76(27.3)$ & 30 (11.6) \\
\hline$>3$ years & $74(26.6)$ & $16(6.2)$ \\
\hline Were you taken through induction and orientation? & $\mathrm{n}=\mathbf{2 8 1}$ & $\mathrm{n}=265$ \\
\hline Yes & $159(56.6)$ & $204(77.0)$ \\
\hline No & $122(43.4)$ & $61(23.0)$ \\
\hline Provided job description & $\mathrm{n}=\mathbf{2 8 1}$ & $\mathrm{n}=\mathbf{2 6 5}$ \\
\hline Yes & $100(35.6)$ & $146(55.1)$ \\
\hline No & $181(64.4)$ & $119(44.9)$ \\
\hline Provided scheme of service/staff manual? & $n=281$ & $n=265$ \\
\hline Yes & $47(16.7)$ & $69(26.0)$ \\
\hline No & $234(83.3)$ & $196(74.0)$ \\
\hline Was documentation of credentials requested after hiring? & $n=281$ & $n=265$ \\
\hline Yes & $277(98.6)$ & $262(98.9)$ \\
\hline No & $4(1.4)$ & $3(1.1)$ \\
\hline Link to supervisor after hiring & $\mathrm{n}=\mathbf{2 8 1}$ & $n=265$ \\
\hline Yes & 201 (71.5) & $191(72.1)$ \\
\hline No & $80(28.5)$ & $74(27.9)$ \\
\hline Bonded to employer & $\mathrm{n}=\mathbf{2 8 1}$ & $n=265$ \\
\hline Yes & $33(11.7)$ & $102(38.5)$ \\
\hline No & $248(88.3)$ & $163(61.5)$ \\
\hline Duration of bonding & $3.03+\ldots .63$ & $3.8+\_1.33$ \\
\hline Type of HTI graduated from first time & $\mathrm{N}=\mathbf{2 8 1}$ & $\mathrm{N}=265$ \\
\hline Government-owned HTIs & $266(94.7)$ & $220(83.0)$ \\
\hline Private HTIs & $15(5.3)$ & $45(17.0)$ \\
\hline
\end{tabular}

a In the public sector in Nigeria, an employee is typically given an offer of temporary appointment with the expectation that within 2 years of satisfactory performance, the appointment is confirmed to 'full employment' status.

b. Bonding employs a health worker is employed by contract agreement stipulating that the worker is mandated to work for a minimum number of years in the government system, especially when the government sponsored the worker's training. 


\section{Deployment of Health Workers}

When asked if deployment was planned and systematic in their LGA, most health workers responded "yes" (Bauchi 67\%, Cross River 45\%). About one fifth (21\%) and one third (30\%) of workers, respectively, in Bauchi and Cross River admitted, however, not knowing whether deployment in their LGA was planned and systematic. Bauchi's majority $(80 \%)$ was satisfied with its LGA deployment process, while less than half (49\%) in Cross River was. In both states, it was rare for health workers to request a posting (Bauchi 13\%, Cross River 9\%) or be consulted prior to posting (Bauchi 12\%, Cross River 5\%). The most important things workers liked about their health facility after they were posted were 'friendly/supportive staff' (Bauchi 77\%, Cross River $63 \%$ ) followed by 'love for community/people' (Bauchi 75\%, Cross River 59\%). In both states, a majority stated that their posting improved their performance (Bauchi 96\%, Cross River 93\%) and offered opportunities to identify further development (Bauchi 89\%, Cross River 93\%). Only about half (Bauchi 49\%, Cross River 52\%) of respondents in both states, however, have had opportunities for sponsored trainings after posted to their health facility.

Table 9: Deployment practices

\begin{tabular}{|l|c|c|}
\hline Characteristic & $\begin{array}{c}\text { Bauchi } \\
n(\%)\end{array}$ & $\begin{array}{c}\text { Cross River } \\
n(\%)\end{array}$ \\
\hline Is deployment in your LGA planned and systematic? & $\mathrm{n}=281$ & $\mathrm{n}=265$ \\
\hline Yes & $189(67.3)$ & $121(45.7)$ \\
\hline No & $32(11.4)$ & $65(24.5)$ \\
\hline Don't know & $60(21.4)$ & $79(29.8)$ \\
\hline Satisfied with deployment process in your LGA? & $\mathrm{n}=281$ & $\mathrm{n}=265$ \\
\hline Yes & $226(80.4)$ & $129(48.7)$ \\
\hline No & $45(16.0)$ & $93(35.1)$ \\
\hline Indifferent & $10(3.6)$ & $43(16.2)$ \\
\hline Did you request to be posted to this facility? & $\mathrm{n}=281$ & $\mathrm{n}=265$ \\
\hline Yes & $37(13.2)$ & $24(9.1)$ \\
\hline No & $244(86.8)$ & $241(90.9)$ \\
\hline Consulted before posting? & $\mathrm{n}=244$ & $\mathrm{n}=241$ \\
\hline Yes & $28(11.5)$ & $13(5.4)$ \\
\hline No & $216(88.5)$ & $228(94.6)$ \\
\hline What do you like about this facility following your posting? & $\mathrm{n}=281$ & $\mathrm{n}=265$ \\
\hline Recognition of good performance & $156(55.5)$ & $71(26.8)$ \\
\hline Friendly/supportive staff & $217(77.2)$ & $167(63.0)$ \\
\hline Love for community/people & $210(74.7)$ & $157(59.2)$ \\
\hline Working with less supervision & $7(2.5)$ & $9(3.4)$ \\
\hline Availability of accommodation & $27(9.6)$ & $18(6.8)$ \\
\hline Cheap accommodation & $14(5.0)$ & $20(7.5)$ \\
\hline Availability of basic amenities & $49(17.4)$ & $40(15.1)$ \\
\hline Accessibility to the city & $69(24.6)$ & $46(17.4)$ \\
\hline Accessibility to school for children & $57(20.3)$ & $59(22.3)$ \\
\hline Working with more supervision & $63(22.4)$ & $43(16.2)$ \\
\hline Has posting improved your performance? & $\mathrm{n}=281$ & $\mathrm{n}=265$ \\
\hline Yes & $269(95.7)$ & $247(93.2)$ \\
\hline No & $12(4.3)$ & $18(6.8)$ \\
\hline Offered opportunities to identify further development? & $\mathrm{n}=281$ & $\mathrm{n}=265$ \\
\hline Yes & $249(88.6)$ & $245(92.5)$ \\
\hline No & $32(11.4)$ & $20(7.5)$ \\
\hline At this posting, have you had opportunity for sponsored training? & $\mathrm{n}=281$ & $\mathrm{n}=265$ \\
\hline Yes & $137(48.8)$ & $138(52.1)$ \\
\hline No & $144(51.2)$ & $127(47.9)$ \\
\hline & & \\
\hline & & \\
\hline
\end{tabular}

\section{Gender Considerations in Hiring and Deployment}

In both states, about one tenth of respondents (Bauchi 12\%, Cross River 8\%) believe the HRH hiring process was discriminatory in terms of gender, and of those who stated so, more than half (56\%) from Bauchi and all (100\%) from Cross River believed the discrimination was against men. 
Most respondents (Bauchi 75\%, Cross River 76\%) asserted that female and male health workers have equal opportunities to be hired for roles in their state.

Only 27 percent and 5.3 percent of respondents, respectively, in Bauchi and Cross River agree there was gender preference in deployment to specific LGAs. Most (85\%) of respondents in Cross River reported no gender preference in deployment to specific LGAs. When asked if there were special considerations in deployment, due to pregnancy or recent childbirth, only 14 percent and eight percent, respectively, responded in the affirmative in Bauchi and Cross River. In Bauchi, the most common consideration for deployment was "leave from work" (4\%) while in Cross River the most common consideration was "proximity to where you live" (2\%). In both states, health workers were rarely ever discriminated against during deployment due to pregnancy or childbirth (Bauchi $8 \%$, Cross River 4\%).

Table 10: Gender preferences and considerations in hiring and deployment

\begin{tabular}{|l|c|c|}
\hline Characteristic & $\begin{array}{c}\text { Bauchi } \\
\mathrm{n}(\%)\end{array}$ & $\begin{array}{c}\text { Cross River } \\
\mathrm{n}(\%)\end{array}$ \\
\hline Do you think the HRH process is discriminatory based on gender? & $\mathrm{n}=281$ & $\mathrm{n}=265$ \\
\hline Agree & $34(12.1)$ & $22(8.3)$ \\
\hline Disagree & $218(77.6)$ & $220(83.0)$ \\
\hline Undecided & $29(10.3)$ & $23(8.7)$ \\
\hline Which gender does it discriminate against? & $\mathrm{n}=34$ & $\mathrm{n}=22$ \\
\hline Male & $19(55.9)$ & $22(8.3)$ \\
\hline Female & $15(44.1)$ & - \\
\hline Do female workers have equal hiring opportunities in your state? & $\mathrm{n}=281$ & $\mathrm{n}=265$ \\
\hline Yes & $211(75.1)$ & $200(75.5)$ \\
\hline No & $53(18.9)$ & $50(18.9)$ \\
\hline Undecided & $17(6.0)$ & $15(5.7)$ \\
\hline Are there gender preferences in deployment to specific LGAs? & $\mathrm{n}=281$ & $\mathrm{n}=265$ \\
\hline Yes & $75(26.7)$ & $14(5.3)$ \\
\hline No & $135(48.0)$ & $226(85.3)$ \\
\hline Don't know & $71(25.3)$ & $25(9.4)$ \\
\hline $\begin{array}{l}\text { Are there gender deployment preferences for specific health facility } \\
\text { types? }\end{array}$ & $\mathrm{n}=281$ & $\mathrm{n}=265$ \\
\hline Yes & $94(33.5)$ & $9(3.4)$ \\
\hline No & $124(44.1)$ & $232(87.5)$ \\
\hline Don't know & $63(22.4)$ & $24(9.1)$ \\
\hline $\begin{array}{l}\text { Special deployment considerations due to pregnancy or recent } \\
\text { childbirth? }\end{array}$ & $\mathrm{N}=281$ & $\mathrm{n}=265$ \\
\hline Yes & $40(14.2)$ & $22(8.3)$ \\
\hline No & $241(85.8)$ & $243(91.7)$ \\
\hline What types? & $\mathrm{n}=281$ & $\mathrm{n}=265$ \\
\hline No consideration/Not applicable & $241(85.8)$ & $243(91.7)$ \\
\hline Leave from work & $11(3.9)$ & $3(1.1)$ \\
\hline Proximity to where you live & $5(1.8)$ & $6(2.3)$ \\
\hline Facility with creche & $6(2.1)$ & $1(0.4)$ \\
\hline Maternity friendly workplace & $16(5.7)$ & $4(1.5)$ \\
\hline Others & $2(0.7)$ & $8(3.0)$ \\
\hline $\begin{array}{l}\text { Have you experienced deployment discrimination due to pregnancy } \\
\text { or childbirth? }\end{array}$ & $\mathrm{n}=281$ & $\mathrm{n}=265$ \\
\hline Yes & $21(7.5)$ & $10(3.8)$ \\
\hline No & $210(74.7)$ & $219(82.6)$ \\
\hline Not applicable & $50(17.8)$ & $36(13.6)$ \\
\hline $\begin{array}{l}\text { Missed posting to another facility because of maternity leave } \\
\text { or wife just given birth? }\end{array}$ & $\mathrm{n}=281$ & $\mathrm{n}=265$ \\
\hline Yes & $9(3.2)$ & $4(1.5)$ \\
\hline No & $211(75.1)$ & $214(80.8)$ \\
\hline Not applicable (no children) & $61(21.7)$ & $47(17.7)$ \\
\hline & & \\
\hline
\end{tabular}




\section{Retention}

Two major domains assessed health system retention capacities in Bauchi and Cross River: staff workload (and associated characteristics), and remuneration, incentives and compensation.

\section{Staff workloads}

Slightly over half (Bauchi 52\%, Cross River 55\%) of FLHWs in both states worked up to 40 hours every week. About one third in each state (Bauchi 36\%, Cross River 36\%) spent more than 50 hours at work every week. More Cross River respondents (72\%) worked shifts than in Bauchi (58\%). The proportion of health workers who worked one to two shifts in the 30 days preceding the study in Cross River (22\%) was twice that of Bauchi (10\%). The proportion of health workers in both states who worked more than three shifts was the same (10\%). Outreach activities appear more pronounced in Cross River, where more than half (56\%) of workers had conducted at least three outreaches in the past 30 days, compared to Bauchi (31\%). Most (60\%) Bauchi respondents asserted that their health facility attended to at least 150 patients weekly, while in Cross River only a few (5.3\%) respondents reported their facility attending to at least 150 patients weekly. Most health workers in Cross River (89.1\%) reported personally seeing 20 patients or fewer, while most (60\%) health workers in Bauchi reported seeing at least 41 patients in the last week. Overall, 64 percent of health workers in Bauchi and 54 percent in Cross River reported personally attending less than half of their facility's patients.

Table 11: Staff workloads

\begin{tabular}{|c|c|c|}
\hline Characteristic & $\begin{array}{c}\text { Bauchi } \\
\text { n (\%) }\end{array}$ & $\begin{array}{c}\text { Cross River } \\
\text { n (\%) }\end{array}$ \\
\hline Hours worked weekly (personally) & $\mathrm{n}=281$ & $n=265$ \\
\hline$<40$ hours & $50(17.8)$ & $42(15.8)$ \\
\hline 40 hours & $96(34.2)$ & $105(39.6)$ \\
\hline 41 to 50 hours & $35(12.5)$ & $24(9.1)$ \\
\hline$>50$ hours & $100(35.6)$ & $94(35.5)$ \\
\hline Do you work shifts & $n=281$ & $n=265$ \\
\hline Yes & $163(58.0)$ & $191(72.1)$ \\
\hline No & $118(42.0)$ & $74(27.9)$ \\
\hline Shifts in the past 30 days & $n=281$ & $\mathrm{n}=265$ \\
\hline No shift & $118(42.0))$ & $74(27.9)$ \\
\hline 1 to 2 shifts & $28(10.0)$ & $59(22.3)$ \\
\hline 3 shifts & $105(37.4)$ & $106(40.0)$ \\
\hline$>3$ shifts & $30(10.7)$ & $26(9.8)$ \\
\hline Outreaches in the past 30 days & $n=281$ & $n=265$ \\
\hline None & $80(28.5)$ & - \\
\hline 1 to 2 outreaches & $86(30.6)$ & $116(43.8)$ \\
\hline 3 outreaches or more & $115(40.9)$ & $149(56.2)$ \\
\hline Patients attended weekly at facility & $n=281$ & $n=265$ \\
\hline 0 to 49 patients & $34(12.1)$ & $215(81.1)$ \\
\hline 50 to 149 patients & $79(28.1)$ & $36(13.6)$ \\
\hline 150 patients or more & $168(59.8)$ & $14(5.3)$ \\
\hline Patients personally seen in last week & $n=281$ & $n=265$ \\
\hline 0 to 20 patients & $60(21.4)$ & $236(89.1)$ \\
\hline 21 to 40 patients & $60(21.4)$ & $21(7.9)$ \\
\hline 41 patients or more & $161(57.3)$ & $8(3.0)$ \\
\hline Mean & 68 & 11 \\
\hline Workload (\% of facility workload by FLHW surveyed ) & $n=281$ & $n=265$ \\
\hline$<50 \%$ workload & $180(64.1)$ & $144(54.3)$ \\
\hline $50 \%$ or more & $101(35.9)$ & $121(45.7)$ \\
\hline Is there a need for more staff at facility? & $n=281$ & $n=265$ \\
\hline Yes & $264(94.0)$ & $229(86.4)$ \\
\hline No & $17(6.0)$ & $36(13.6)$ \\
\hline Cadre of staff needed & $n=264$ & $\mathrm{n}=\mathbf{2 2 9}$ \\
\hline JCHEW & $205(77.7)$ & $158(69.0)$ \\
\hline CHEW & $221(83.7)$ & $198(86.5)$ \\
\hline
\end{tabular}




\begin{tabular}{|l|c|c|}
\hline CHO & $120(45.5)$ & $67(29.3)$ \\
\hline Nurse & $149(56.4)$ & $43(18.8)$ \\
\hline Midwife & $192(72.7)$ & $81(35.4)$ \\
\hline
\end{tabular}

\section{Remuneration, incentives, and compensation}

Health workers were asked their opinion of whether their salary was fair. More than half (55\%) of Bauchi respondents agreed their salary was fair, while only 39 percent agreed in Cross River. Although a few respondents were neutral in both states, the proportion who disagreed in Cross River (59\%) was twice that of Bauchi (27\%). When asked to rate their salary, more respondents in Cross River (45\%) than in Bauchi (22\%) rated their salary poor. Most workers in Bauchi $(85 \%)$ earned 100,000 Naira or less monthly, while in Cross River 71 percent of workers earned $\mathrm{N} 100,000$ or less.

In Bauchi 87 percent of respondents reportedly experienced delays in salary payments in the last 12 months. Conversely, in Cross River only a little more than one tenth (13\%) reportedly experienced such delays. Delays were more short-lived in Bauchi, where 96 percent reported their lasting less than two weeks, while in Cross River 82 percent reported delays lasting two weeks or longer. About one third (35\%) and one tenth (12\%) of respondents in in Bauchi and Cross River, respectively, reported an alternative source of income. The most common alternative source of income in both states was farming (Bauchi 24\%, Cross River 9\%). Unlike in Bauchi, where almost half $(47 \%)$ believed there are not enough promotion opportunities, most repondents in Cross River (78\%) believe there are sufficient opportunities for promotion.

Table 12: Remuneration, incentives and compensation

\begin{tabular}{|l|c|c|}
\hline Characteristic & $\begin{array}{c}\text { Bauchi } \\
\mathrm{n}(\%)\end{array}$ & $\begin{array}{c}\text { Cross River } \\
\mathrm{n}(\%)\end{array}$ \\
\hline Salary package is fair & $\mathrm{n}=281$ & $\mathrm{n}=265$ \\
\hline Agree & $155(55.2)$ & $102(38.5)$ \\
\hline Disagree & $77(27.4)$ & $155(58.5)$ \\
\hline Neutral & $49(17.4)$ & $8(3.0)$ \\
\hline Sufficient promotion opportunities with this employer & $\mathrm{n}=281$ & $\mathrm{n}=265$ \\
\hline Agree & $105(37.4)$ & $206(77.7)$ \\
\hline Disagree & $133(47.3)$ & $46(17.4)$ \\
\hline Neutral & $43(15.3)$ & $13(4.9)$ \\
\hline Monthly income & $\mathrm{n}=281$ & $\mathrm{n}=265$ \\
\hline$<50,000$ & $117(41.6)$ & $80(30.2)$ \\
\hline 50,000 to 100,000 & $129(45.9)$ & $109(41.1)$ \\
\hline 101,000 to 150,000 & $28(10.0)$ & $63(23.8)$ \\
\hline 151,000 and above & $7(2.5)$ & $13(4.9)$ \\
\hline How would you rate your salary? & $\mathrm{n}=281$ & $\mathrm{n}=265$ \\
\hline Very good & $20(7.1)$ & $8(3.0)$ \\
\hline Good & $65(23.1)$ & $29(10.9)$ \\
\hline Fair & $133(47.3)$ & $109(41.1)$ \\
\hline Poor & $63(22.4)$ & $119(44.9)$ \\
\hline Any delay in salary in past 12 months & $\mathrm{n}=281$ & $\mathrm{n}=265$ \\
\hline Yes & $244(86.8)$ & $34(12.8)$ \\
\hline No & $35(12.5)$ & $230(86.8)$ \\
\hline Don't know & $2(0.7)$ & $1(0.4)$ \\
\hline How long was the delay & $\mathrm{n}=244$ & $\mathrm{n}=34$ \\
\hline$<2$ weeks & $235(96.3)$ & $6(17.6)$ \\
\hline 2 to 4 weeks & $3(1.1)$ & $9(26.5)$ \\
\hline 1 to 2 months & $2(0.7)$ & $9(26.5)$ \\
\hline 3 months and above & $4(1.4)$ & $10(29.4)$ \\
\hline Alternative source of income & $\mathrm{n}=281$ & $\mathrm{n}=265$ \\
\hline None & $184(65.5)$ & $233(87.9)$ \\
\hline Petty trading & $22(7.8)$ & $8(3.0)$ \\
\hline Farming & $67(23.8)$ & $23(8.7)$ \\
\hline Others & $8(2.9)$ & $1(0.4)$ \\
\hline & & \\
\hline & & 25 \\
\hline
\end{tabular}




\section{Health Managers and Policymakers}

\section{Socio-demographic and background characteristics}

Overall, Bauchi had a younger population of managers, with mean age of 44 . When disaggregated, a higher proportion (72\%) of health managers in Cross River were 45 years or older; in Bauchi it was 34 percent. More than half (51\%) of managers in Bauchi were 35 to 44 years of age, while one fourth (25\%) of managers in Cross River belonged to the same age group. In Bauchi, most (72\%) health managers were male, whereas in Cross River about three quarters (75\%) were female. In Bauchi, most managers were married (98\%) and Muslim (84\%). Similarly, most health managers in Cross River were married (86\%) and Christian (100\%). In both states, most health managers interviewed worked in health facilities (Bauchi 93\%, Cross River 63\%), with other managers interviewed working in Health departments and ministries, or other departments and agencies in the health sector. Health managers had served in that role in both states for a mean of four and a half years. Managers in Cross River generally reported higher levels of education, with 21 percent and 14 percent possessing undergraduate and postgraduate degrees, respectively. Conversely, only four percent of managers in Bauchi had undergraduate university degrees, while none possessed a postgraduate degree.

Table 13: Managers' and policymakers' socio-demographic and background characteristics

\begin{tabular}{|c|c|c|}
\hline Characteristic & $\begin{array}{c}\text { Bauchi } \\
\text { n (\%) }\end{array}$ & $\begin{array}{c}\text { Cross River } \\
\mathrm{n}(\%)\end{array}$ \\
\hline Age & $n=123$ & $n=112$ \\
\hline$<35 y r s$ & $18(14.6)$ & $2(1.8)$ \\
\hline 35 to 44 years & $63(51.2)$ & $29(25.9)$ \\
\hline 45 years and above & $42(34.1)$ & $81(72.3)$ \\
\hline Gender & $n=123$ & $n=112$ \\
\hline Male & $88(71.5)$ & $28(25.0)$ \\
\hline Female & $35(28.5)$ & $84(75.0)$ \\
\hline Marital Status & $n=123$ & $n=112$ \\
\hline Single & $2(1.6)$ & $10(8.9)$ \\
\hline Married & $120(97.6)$ & $96(85.7)$ \\
\hline Separated/Divorced/Widowed & $1(0.8)$ & $6(5.4)$ \\
\hline Religion & $n=123$ & $n=112$ \\
\hline Christian & $20(16.3)$ & $112(100.0)$ \\
\hline Islam & $103(83.7)$ & - \\
\hline Type of Organization & $n=123$ & $n=112$ \\
\hline Health facility & $114(92.7)$ & $75(67.0)$ \\
\hline Health department & $1(0.8)$ & $5(4.5)$ \\
\hline MDAs & $1(0.8)$ & $17(15.2)$ \\
\hline Others & $7(5.7)$ & $15(13.4)$ \\
\hline How long have you worked in this organization & 4.5 & 4.5 \\
\hline Highest Education Qualification & $n=123$ & $n=112$ \\
\hline Certificate & $20(16.3)$ & $14(12.5)$ \\
\hline Diploma & $62(50.4)$ & $25(22.3)$ \\
\hline Higher Diploma & $24(19.5)$ & $32(28.6)$ \\
\hline Midwife & $1(0.8)$ & $2(1.8)$ \\
\hline Nurse & $1(0.8)$ & - \\
\hline Nurse and Midwife & $8(6.5)$ & - \\
\hline University (B.Sc) & $5(4.1)$ & $23(20.5)$ \\
\hline Masters' degree/postgraduate & $2(1.6)$ & $16(14.3)$ \\
\hline
\end{tabular}

\section{Manager Reports of Hiring Practices}

Health managers were assessed on their knowledge and awareness of hiring, deployment, and retention policies, practices, and procedures in Bauchi and Cross River, according to policy implementation and practice in their states, position and vacancy advertising, and the application process including interviews and documentation. 
Policy implementation and practice in the state

When managers were asked if they were aware of any HRH recruitment policies in their state, 48 percent of managers in Bauchi and 47 percent in Cross River responded in the affirmative, although a sizable proportion (Bauchi 42\%, Cross River 39\%) admitted that they did not know whether any such policies existed. Of those who responded affirmatively, the majority (Bauchi $62 \%$, Cross River $66 \%$ ) asserted that the policies were being implemented in their state. In both states, about half of health managers believe policy addresses different categories of individuals (Bauchi 52\%, Cross River 48\%) and that the state uses a quota system for HRH hiring (Bauchi $54 \%$, Cross River 51\%). Most (Bauchi 85\%, Cross River 88\%) managers affirmed that their health workers were hired based on merit. About half (Bauchi 55\%, Cross River 50\%) of managers reported HRH hiring as need arises, with a substantial proportion (Bauchi 42\%, Cross River 49\%) believing there is no recruitment strategy in the state. To further support this, most (Bauchi 74\%, Cross River $80 \%$ ) asserted that there was no recruitment in their state in the preceding year, and for most (Bauchi 95\%, Cross River 81\%), their state's last recruitment was over three years ago.

Table 14: State policy implementation and practice

\begin{tabular}{|l|c|c|}
\hline Characteristic & $\begin{array}{c}\text { Bauchi } \\
\mathrm{n}(\%)\end{array}$ & $\begin{array}{c}\text { Cross River } \\
\mathrm{n}(\%)\end{array}$ \\
\hline Is there a specific recruitment policy for HRH in the state? & $\mathrm{n}=123$ & $\mathrm{n}=112$ \\
\hline Yes & $60(48.8)$ & $53(47.3)$ \\
\hline No & $11(8.9)$ & $15(13.4)$ \\
\hline Don't know & $52(42.3)$ & $44(39.3)$ \\
\hline Is the policy being implemented in the state? & $\mathrm{n}=60$ & $\mathrm{n}=53$ \\
\hline Yes & $37(61.7)$ & $35(66.0)$ \\
\hline No & $12(20.0)$ & $6(11.3)$ \\
\hline Don't know & $11(18.3)$ & $12(22.6)$ \\
\hline Does the policy provide for different categories of people? & $\mathrm{n}=123$ & $\mathrm{n}=112$ \\
\hline Yes & $64(52.0)$ & $54(48.2)$ \\
\hline No & $22(17.9)$ & $20(17.9)$ \\
\hline Don't know & $37(30.1)$ & $38(33.9)$ \\
\hline Does the state use a quota system for HRH hiring? & $\mathrm{n}=123$ & $\mathrm{n}=112$ \\
\hline Yes & $66(53.7)$ & $57(50.9)$ \\
\hline No & $30(24.4)$ & $27(24.1)$ \\
\hline Don't know & $27(22.0)$ & $28(25.0)$ \\
\hline Are health workers hired based on merit/knowledge or skills? & $\mathrm{n}=123$ & $\mathrm{n}=112$ \\
\hline Yes & $105(85.4)$ & $98(87.5)$ \\
\hline No & $10(8.1)$ & $8(7.1)$ \\
\hline Don't know & $8(6.5)$ & $6(5.4)$ \\
\hline How often is HRH recruitment done in the state? & $\mathrm{n}=123$ & $\mathrm{n}=112$ \\
\hline Once a year & $3(2.4)$ & $1(0.9)$ \\
\hline As the need arises & $68(55.3)$ & $56(50.0)$ \\
\hline There is no pattern & $52(42.3)$ & $55(49.1)$ \\
\hline Has there been recruitment in the last 12 months? & $\mathrm{n}=123$ & $\mathrm{n}=112$ \\
\hline Yes & $4(3.3)$ & $15(13.4)$ \\
\hline No & $91(74.0)$ & $90(80.4)$ \\
\hline Don't know & $28(22.8)$ & $7(6.3)$ \\
\hline How many years ago was the last recruitment? & $\mathrm{n}=123$ & $\mathrm{n}=112$ \\
\hline Less than a year & $1(0.8)$ & $13(11.6)$ \\
\hline 1 to 2 years ago & $2(1.6)$ & $6(5.4)$ \\
\hline$>2<3$ years ago & $3(2.4)$ & $2(1.8)$ \\
\hline 3 years or more & $117(95.1)$ & $91(81.3)$ \\
\hline & & \\
\hline
\end{tabular}

Job and vacancy advertising and application process

To ascertain both the efficiency and transparency in the recruitment process, health care managers were asked about the advertising and application processes. A higher proportion of managers in Cross River (84\%) than in Bauchi (44\%) asserted that vacancies were advertised 
during their state's last recruitment. In both states, the most utilized means of advertising was radio (Bauchi 85\%, Cross River 48\%), significantly greater in Bauchi.

Only about one fifth (22\%) of respondents in Bauchi believe there were provisions for internal candidates to apply. Conversely, in Cross River almost half (48\%) of managers believe there are provisions for internal candidates. In Bauchi, only a few managers (24\%) agreed that there are preferences for internal candidates within the health care system, while in Cross River, a higher proportion (48\%) agreed their health care system accommodates internal candidates. Generally, the recruitment exercise appeared to take longer in Cross River. While more than one third (37\%) of managers in Cross River maintained that the last recruitment took one to two weeks, in Cross River a slightly higher proportion (40\%) reported that their last recruitment took more than two months. About 49 percent of managers in Bauchi and 37 percent in Cross River reportedly did not know how long the last recruitment lasted. In both states, most managers (Bauchi 63\%, Cross River $80 \%$ ) agreed that selection criteria were developed for the recruitment.

Table 15: Position and vacancy advertising and application process

\begin{tabular}{|l|c|c|}
\hline Characteristic & $\begin{array}{c}\text { Bauchi } \\
n(\%)\end{array}$ & $\begin{array}{c}\text { Cross River } \\
n(\%)\end{array}$ \\
\hline Was job vacancy advertised during last recruitment? & $n=123$ & $n=112$ \\
\hline Yes & $54(43.9)$ & $95(83.9)$ \\
\hline No & $35(28.5)$ & $9(8.0)$ \\
\hline Don't know & $34(27.6)$ & $9(8.0)$ \\
\hline Means of advertising* ${ }^{*}$ 'Multiple responses allowed & $n=54$ & $n=94$ \\
\hline Daily Newspaper & $8(14.8)$ & $18(19.1)$ \\
\hline Online/internet jobsites & - & - \\
\hline Radio & $46(85.2)$ & $45(47.9)$ \\
\hline Television & $26(48.1)$ & $17(15.2)$ \\
\hline Church or mosque announcement & - & - \\
\hline Word-of-mouth & - & - \\
\hline Are there provisions for internal candidates to apply? & $\mathrm{n}=123$ & $\mathrm{n}=112$ \\
\hline Yes & $27(22.0)$ & $48(42.9)$ \\
\hline No & $38(30.9)$ & $39(34.8)$ \\
\hline Don't know & $58(47.2)$ & $25(22.3)$ \\
\hline Are there any preferences for internal candidates? & $\mathrm{n}=123$ & $\mathrm{n}=112$ \\
\hline Yes & $29(23.6)$ & $54(48.2)$ \\
\hline No & $41(33.3)$ & $31(27.7)$ \\
\hline Don't know & $53(43.1)$ & $27(24.1)$ \\
\hline How long did the last recruitment exercise take? & $\mathrm{n}=123$ & $\mathrm{n}=112$ \\
\hline 1 to 2 weeks & $46(37.4)$ & $8(7.1)$ \\
\hline 1 to 2 months & $4(3.3)$ & $10(8.9)$ \\
\hline 3 to 4 weeks & $1(0.8)$ & $8(7.1)$ \\
\hline More than 2 months & $12(9.8)$ & $45(40.2)$ \\
\hline Don't know & $60(48.8)$ & $41(36.6)$ \\
\hline Was a selection criterion developed for the recruitment? & $\mathrm{n}=123$ & $\mathrm{n}=112$ \\
\hline Yes & $78(63.4)$ & $89(79.5)$ \\
\hline No & $8(6.5)$ & $4(3.6)$ \\
\hline Don't know & $37(30.1)$ & $19(17.0)$ \\
\hline
\end{tabular}

\section{Interview and documentation process}

Most health care managers stated that during their state's last recruitment exercise an interview panel was constituted (Bauchi 81\%, Cross River 96\%) and potential candidates were interviewed (Bauchi 91\%, Cross River 99\%), but a lower proportion (Bauchi 72\%, Cross River 61\%) reported that their PHC Coordinator was informed of the interviews' results before new hires were deployed. Most (Bauchi 86\%, Cross River 92\%) agreed that certificates of selected candidates were verified during interview. A lower proportion (Bauchi 62\%, Cross River 47\%) acknowledged that reference checks were conducted on selected candidates, however. 
Most health managers believe new employees were given an orientation within the first three months of employment (Bauchi 68\%, Cross River 75\%), after an offer letter detailing their job designation (Bauchi $87 \%$, Cross River $87 \%$ ), along with notices for resumption of duty (Bauchi 95\%, Cross River 99\%). In Bauchi, about one quarter (26\%) reported that suggestions were provided to candidates not selected, while only 15 percent in Cross River did.

Table 16: Interview and documentation process

\begin{tabular}{|c|c|c|}
\hline Characteristic & $\begin{array}{l}\text { Bauchi } \\
\text { n (\%) }\end{array}$ & $\begin{array}{l}\text { Cross River } \\
\mathrm{n}(\%)\end{array}$ \\
\hline Was an interview panel constituted? & $n=123$ & $n=112$ \\
\hline Yes & $99(80.5)$ & $108(96.4)$ \\
\hline No & $2(1.6)$ & $1(0.9)$ \\
\hline Don't know & $22(17.9)$ & $3(2.7)$ \\
\hline Who are members of the interview panel?* & $n=99$ & $n=108$ \\
\hline Dir Admin SMOH & $43(43.4)$ & $12(11.1)$ \\
\hline Officer from SPHCDA & $69(69.7)$ & $4(3.7)$ \\
\hline LGA PHC Coordinator & $68(68.7)$ & $14(12.5)$ \\
\hline Rep of NMC & $12(12.1)$ & - \\
\hline Rep from CHPBN & $13(13.1)$ & - \\
\hline LGSC & $26(26.3)$ & $53(49.1)$ \\
\hline Dir Nursing, SMOH & $9(9.1)$ & $3(2.7)$ \\
\hline Dir of PHC, SMOH & $13(13.1)$ & $2(1.9)$ \\
\hline Were potential candidates interviewed? & $n=123$ & $n=112$ \\
\hline Yes & $90(73.2)$ & 107 (95.5) \\
\hline No & $4(3.3)$ & - \\
\hline Don't know & $5(4.1)$ & $1(0.9)$ \\
\hline No Response & $24(19.5)$ & $4(3.6)$ \\
\hline $\begin{array}{l}\text { Were key stakeholders such as PHC Coordinator informed } \\
\text { of the interview before deployment? }\end{array}$ & $n=123$ & $n=112$ \\
\hline Yes & $72(58.5)$ & $66(58.9)$ \\
\hline No & $3(2.4)$ & $14(12.5)$ \\
\hline Don't know & $24(19.5)$ & $28(25.0)$ \\
\hline No Response & $24(19.5)$ & $4(3.6)$ \\
\hline Were certificates of selected candidates verified? & $n=123$ & $n=112$ \\
\hline Yes & $106(86.2)$ & $103(92.0)$ \\
\hline No & $2(1.6)$ & - \\
\hline Don't know & $15(12.2)$ & $9(8.0)$ \\
\hline Was there any reference check on the selected candidates? & $n=123$ & $\mathrm{n}=112$ \\
\hline Yes & $79(64.2)$ & $53(47.3)$ \\
\hline No & $12(9.8)$ & $11(9.8)$ \\
\hline Don't know & $32(26.0)$ & $48(42.9)$ \\
\hline $\begin{array}{l}\text { Was there an orientation for new employees within their first } \\
3 \text { months? }\end{array}$ & $n=123$ & $n=112$ \\
\hline Yes & $84(68.3)$ & $84(75.0)$ \\
\hline No & $26(21.1)$ & $20(17.9)$ \\
\hline Don't know & $13(10.6)$ & $8(7.1)$ \\
\hline Was there an offer letter detailing job designation? & $n=123$ & $n=112$ \\
\hline Yes & $108(87.8)$ & $98(87.5)$ \\
\hline No & $9(7.3)$ & $6(5.4)$ \\
\hline Don't know & $6(4.9)$ & $8(7.1)$ \\
\hline Were notices given for resumption of duty/appointments? & $n=123$ & $n=112$ \\
\hline Yes & $117(95.1)$ & $111(99.1)$ \\
\hline No & $3(2.4)$ & - \\
\hline Don't know & $3(2.4)$ & $1(0.9)$ \\
\hline Was there feedback for candidates not selected? & $n=123$ & $n=112$ \\
\hline Yes & $32(26.0)$ & $17(15.2)$ \\
\hline No & $61(49.6)$ & 55 (49.1) \\
\hline Don't know & $30(24.4)$ & $40(35.7)$ \\
\hline
\end{tabular}




\section{Health Manager Reporting of Deployment Policies and Practices}

About one third of managers (Bauchi 35\%, Cross River 36\%) did not know if a deployment policy for their state existed, while more than half $(53 \%)$ in Bauchi and about 44 percent in Cross River were aware of one. When managers were asked if deployment plans aligned with sector needs and demands, half (50\%) in Bauchi and 45 percent in Cross River responded in the affirmative. The most common elements of both states' deployment plans were: list of health facilities with HRH gaps (Bauchi 92\%, Cross River 90\%), HRH cadre needed (Bauchi 82\%, Cross River 43\%), and deployment strategy per services needed (Bauchi 43\%, Cross River 31\%). More than half of health managers in both states asserted that the state or LGA redistributes staff by workload projections (Bauchi 64\%, Cross River 54\%). Similarly, nearly half of managers in both states (Bauchi 46\%, Cross River 47\%) believe workers are unevenly distributed among the different levels of care. The most prevalent reasons attributed for this poor distribution include inadequate skilled manpower (Bauchi 63\%, Cross River 59\%), refusals of remote postings (Bauchi 56\%, Cross River 55\%), and urban preference (Bauchi 49\%, Cross River 55\%). Other reasons advanced included political interference (Bauchi 67\%, Cross River 45\%) and favoritism (Bauchi 67\%, Cross River 45\%). Political interference appeared stronger in Bauchi than in Cross River. More than half of health managers in both states reported that periodic review and assessment of deployment and distribution trends were conducted as need arose (Bauchi 55\%, Cross River 55\%).

Table 17: Managers' reporting of deployment policies and practices

\begin{tabular}{|c|c|c|}
\hline Characteristic & $\begin{array}{c}\text { Bauchi } \\
\text { n (\%) }\end{array}$ & $\begin{array}{c}\text { Cross River } \\
\mathrm{n}(\%)\end{array}$ \\
\hline Is there a staff deployment policy in the state? & $n=123$ & $n=112$ \\
\hline Yes & $66(53.7)$ & $49(43.8)$ \\
\hline No & $14(11.4)$ & $23(20.5)$ \\
\hline Don't know & $43(35.0)$ & $40(35.7)$ \\
\hline Are deployment plans developed periodically to align with needs? & $n=123$ & $n=112$ \\
\hline Yes & $61(49.6)$ & $50(44.6)$ \\
\hline No & $15(12.2)$ & $16(14.3)$ \\
\hline Don't know & $47(38.2)$ & $46(41.1)$ \\
\hline What are the contents of the deployment plans? * & $n=62$ & $\mathrm{n}=62$ \\
\hline List of Health Facilities with HRH gaps & $56(91.8)$ & $45(90.0)$ \\
\hline Cadre of HRH needed & $50(82.0)$ & $48(42.9)$ \\
\hline Deployment strategy as per services needed & $26(42.6)$ & $35(31.3)$ \\
\hline Incentives to attract health workers to underserved areas & $13(21.3)$ & $14(12.5)$ \\
\hline Strategies for implementation of incentive plan & $12(19.7)$ & $12(10.7)$ \\
\hline Are there periodic workload analysis of HRH in the public sector? & $n=123$ & $n=112$ \\
\hline Yes & $75(61.0)$ & $54(48.2)$ \\
\hline No & $21(17.1)$ & $19(17.0)$ \\
\hline Don't know & $27(22.0)$ & $39(34.8)$ \\
\hline Does the state/LGA redistribute staff based on workload projections? & $n=123$ & $n=112$ \\
\hline Yes & $79(64.2)$ & $61(54.5)$ \\
\hline No & $30(24.4)$ & $26(23.2)$ \\
\hline Don't know & $14(11.4)$ & $25(22.3)$ \\
\hline Are health workers unevenly distributed among levels of care? & $n=123$ & $\mathrm{n}=112$ \\
\hline Yes & $57(46.3)$ & $53(47.3)$ \\
\hline No & $39(31.7)$ & $43(38.4)$ \\
\hline Don't know & $27(22.0)$ & $16(14.3)$ \\
\hline Reasons for maldistribution & $n=57$ & $n=53$ \\
\hline Inadequate skilled manpower & $36(63.2)$ & $31(58.5)$ \\
\hline Refusals to go to hard-to-reach areas & $32(56.1)$ & $29(54.7)$ \\
\hline Preference for urban areas & $28(49.1)$ & $29(54.7)$ \\
\hline Difference in salary structure & $15(26.3)$ & $6(11.3)$ \\
\hline Political interference & $38(66.7)$ & $24(45.3)$ \\
\hline Favoritism & $38(66.7)$ & $24(45.3)$ \\
\hline Insecurity & $20(35.1)$ & $13(24.5)$ \\
\hline Absence of incentives & $12(21.1)$ & 8 (15.1) \\
\hline
\end{tabular}




\begin{tabular}{|l|c|c|}
\hline $\begin{array}{l}\text { How often do you conduct periodic review and assessment } \\
\text { of deployment and distribution trends in the state }\end{array}$ & $\mathrm{n}=123$ & $\mathrm{n}=112$ \\
\hline Once within 2 years & $19(15.4)$ & $12(10.7)$ \\
\hline There is no pattern & $12(9.8)$ & $19(17.0)$ \\
\hline As need arises & $68(55.3)$ & $62(55.4)$ \\
\hline Never & $24(19.5)$ & $19(17.0)$ \\
\hline
\end{tabular}

${ }^{*}$ Multiple responses allowed

\section{Managers' reporting of retention}

\section{Policy implementation and incentives}

In both states, more than half of health managers (Bauchi 58\%, Cross River 52\%) were unaware of a staff retention policy, while about one quarter (Bauchi 25\%, Cross River 28\%) were aware of one. A majority of managers in both states believe the policy provides equal opportunities for different categories of people (Bauchi $87 \%$, Cross River $88 \%$ ) and ensures equal retention opportunities for female health workers (Bauchi 84\%, Cross River 94\%).

Performance and rewards were also assessed to identify factors associated with retention. In both states, a majority of managers attested to standards for monitoring of staff performance (Bauchi $70 \%$, Cross River $73 \%$ ). Less than one fifth (Bauchi 18\%, Cross River 16\%), however, admitted that incentives were based on staff performance. The most common monetary incentive available to health workers in both states was "regular payment of salaries" (Bauchi 50\%, Cross River 61\%). Only five percent of managers in Bauchi mentioned rural allowance as a monetary incentive, while more than half $(56 \%)$ in Cross River identified rural allowance as a potent monetary incentive, after "payment of regular salary." Only about one fifth of managers in both states (Bauchi 22\%, Cross River 21\%) agreed that their state has a "ghost worker" problem, i.e. workers on payroll but not actually present and providing services.

Table 18: Retention policy implementation and incentives

\begin{tabular}{|l|c|c|}
\hline Characteristic & $\begin{array}{c}\text { Bauchi } \\
\mathrm{n}(\%)\end{array}$ & $\begin{array}{c}\text { Cross River } \\
\mathrm{n}(\%)\end{array}$ \\
\hline Is there a staff retention policy in the state? & $\mathrm{N}=123$ & $\mathrm{~N}=112$ \\
\hline Yes & $31(25.2)$ & $32(28.6)$ \\
\hline No & $20(16.3)$ & $22(19.6)$ \\
\hline Don't know & $72(58.5)$ & $58(51.8)$ \\
\hline Does the policy provide equal opportunities for retention? & $\mathrm{n}=31$ & $\mathrm{n}=32$ \\
\hline Yes & $27(87.1)$ & $28(87.5)$ \\
\hline No & $3(9.7)$ & $3(9.4)$ \\
\hline Don't know & $1(3.2)$ & $1(3.1)$ \\
\hline Does the policy ensure female workers equal retention opportunities? & $\mathrm{n}=31$ & $\mathrm{n}=32$ \\
\hline Yes & $26(83.9)$ & $30(93.8)$ \\
\hline No & $4(12.9)$ & $1(3.2)$ \\
\hline Don't know & $1(0.8)$ & $1(3.2)$ \\
\hline Are there standards for monitoring of staff performance? & $\mathrm{N}=123$ & $\mathrm{~N}=112$ \\
\hline Yes & $86(69.9)$ & $82(73.2)$ \\
\hline No & $19(15.4)$ & $10(8.9)$ \\
\hline Don't know & $18(14.6)$ & $20(17.9)$ \\
\hline Are there incentives based on staff performance? & $\mathrm{N}=123$ & $\mathrm{~N}=112$ \\
\hline Yes & $22(17.9)$ & $18(16.1)$ \\
\hline No & $93(75.6)$ & $84(75.0)$ \\
\hline Don't know & $8(6.5)$ & $10(8.9)$ \\
\hline What type of monetary incentives are available for motivation? & $\mathrm{N}=22$ & $\mathrm{~N}=18$ \\
\hline Regular payment of salaries & $11(50.0)$ & $11(61.1)$ \\
\hline Rural allowance & $6(4.9)$ & $10(55.6)$ \\
\hline Clinical practice allowance & $4(3.3)$ & $2(11.1)$ \\
\hline What type of non-monetary incentives are available for motivation?* & $\mathrm{N}=22$ & $\mathrm{~N}=18$ \\
\hline Opportunities for career development & $9(40.9)$ & $7(38.9)$ \\
\hline Confirmation of appointment when due & $9(40.9)$ & $8(44.4)$ \\
\hline
\end{tabular}




\begin{tabular}{|l|c|c|}
\hline Training packages tailored to need & $6(27.3)$ & $7(38.9)$ \\
\hline Promotion when due & $8(36.4)$ & $7(38.9)$ \\
\hline Flexible work hours & $5(22.7)$ & $2(11.1)$ \\
\hline Essential equipment are available & $9(40.9)$ & $3(16.7)$ \\
\hline Incentives/award & $12(54.5)$ & $9(50.0)$ \\
\hline Accommodation & - & $4(22.2)$ \\
\hline Does the state have a 'ghost workers' problem? & $\mathrm{N}=123$ & $\mathrm{~N}=112$ \\
\hline Yes & $27(22.0)$ & $23(20.5)$ \\
\hline No & $14(11.4)$ & $25(22.5)$ \\
\hline Don't know & $82(66.7)$ & $64(57.1)$ \\
\hline Are notices given to staff for disengagement from duty/appointments? & $\mathrm{N}=123$ & $\mathrm{~N}=112$ \\
\hline Yes & $72(58.5)$ & $69(61.6)$ \\
\hline No & $18(14.6)$ & $14(12.5)$ \\
\hline Don't know & $33(26.8)$ & $29(25.9)$ \\
\hline${ }^{*}$ Multiple responses allowed & & \\
\hline
\end{tabular}

\section{Managers' Perceptions of Health Worker Satisfaction and Facility Performance}

Manager ratings of facility performance and health worker satisfaction

Most health managers reported performing 'Very Well' on all satisfaction indices. In Bauchi, health managers reported that their health facilities performed best in the "valuing and respecting each other" element (82\%) and least in "recognizing and rewarding good work" and "offering the training needed for staff to succeed at their jobs" (8\% each). In Cross River, health managers reported that their health facilities performed best in "talking to staff regularly to improve their development" (83\%) and least in "recognizing and rewarding good work" (14\%).

Table 19a: Manager ratings of facility health worker satisfaction

\begin{tabular}{|l|c|c|c|c|c|c|}
\hline & \multicolumn{3}{|c|}{ Bauchi (n=123) } & \multicolumn{3}{c|}{ Cross River (n=112) } \\
\hline & $\begin{array}{c}\text { Poor } \\
\text { Performance }\end{array}$ & $\begin{array}{c}\text { Performs } \\
\text { Adequately }\end{array}$ & $\begin{array}{c}\text { Performs } \\
\text { Very Well }\end{array}$ & $\begin{array}{c}\text { Poor } \\
\text { Performance }\end{array}$ & $\begin{array}{c}\text { Performs } \\
\text { Adequately }\end{array}$ & $\begin{array}{l}\text { Performs } \\
\text { Very Well }\end{array}$ \\
\hline $\begin{array}{l}\text { Overall job } \\
\text { satisfaction }\end{array}$ & $2(1.6)$ & $32(26.0)$ & $89(72.4)$ & $8(7.1)$ & $24(21.4)$ & $80(71.4)$ \\
\hline $\begin{array}{l}\text { Proper job } \\
\text { placement }\end{array}$ & $3(2.4)$ & $24(19.5)$ & $96(78.0)$ & $4(3.6)$ & $18(16.1)$ & $90(80.4)$ \\
\hline $\begin{array}{l}\text { Clear job } \\
\text { descriptions }\end{array}$ & $7(5.7)$ & $20(16.3)$ & $96(78.0)$ & $3(2.7)$ & $27(24.1)$ & $82(73.2)$ \\
\hline $\begin{array}{l}\text { Recognizing, } \\
\text { rewarding good } \\
\text { work }\end{array}$ & $10(8.1)$ & $21(17.1)$ & $92(74.8)$ & $16(14.3)$ & $29(25.9)$ & $67(59.8)$ \\
\hline $\begin{array}{l}\text { Supervisors care } \\
\text { about staff } \\
\text { and offer support }\end{array}$ & $2(1.6)$ & $29(23.6)$ & $92(74.8)$ & $6(5.4)$ & $23(20.5)$ & $83(74.1)$ \\
\hline $\begin{array}{l}\text { Regular staff } \\
\text { interaction } \\
\text { to improve staff } \\
\text { development }\end{array}$ & $4(3.3)$ & $23(18.7)$ & $96(78.0)$ & $2(1.8)$ & $17(15.2)$ & $93(83.0)$ \\
\hline $\begin{array}{l}\text { Good overall } \\
\text { morale }\end{array}$ & $5(4.1)$ & $24(19.5)$ & $94(76.4)$ & $2(1.8)$ & $20(17.9)$ & $90(80.4)$ \\
\hline $\begin{array}{l}\text { Each worker } \\
\text { valued, respected }\end{array}$ & $2(1.6)$ & $20(16.3)$ & $\begin{array}{c}101 \\
(82.1)\end{array}$ & $3(2.7)$ & $21(18.8)$ & $88(78.6)$ \\
\hline $\begin{array}{l}\text { Enjoyable, } \\
\text { stimulating } \\
\text { workplace }\end{array}$ & $8(6.5)$ & $18(14.6)$ & $97(78.9)$ & $3(2.7)$ & $24(21.4)$ & $85(75.9)$ \\
\hline $\begin{array}{l}\text { Training for job } \\
\text { success }\end{array}$ & $10(8.1)$ & $16(13.0)$ & $97(78.9)$ & $9(8.0)$ & $17(15.2)$ & $86(76.8)$ \\
\hline
\end{tabular}




\section{Manager ratings of health worker satisfaction}

Health managers rated their perceptions of the extent to which different dimensions of satisfaction are important to their workers. In both states almost all managers (Bauchi 98\%, Cross River 99\%) considered the dimension "placing people in jobs for which they are best suited" "Very Important'. In Bauchi, about 93 percent of managers considered "talking to staff regularly to improve their development" "Very Important'. In Cross River, about 96 percent of managers also rated "having supervisors who care about their staff and offer support" as "Very Important" to their workers.

Table 19b: Manager ratings of importance of satisfaction factors (to employees)

\begin{tabular}{|l|c|c|c|c|c|c|}
\hline & \multicolumn{3}{|c|}{ Bauchi $(\mathrm{n}=123)$} & \multicolumn{3}{c|}{ Cross River (n=112) } \\
\hline & $\begin{array}{c}\text { Not } \\
\text { Important }\end{array}$ & $\begin{array}{c}\text { Somewhat } \\
\text { Important }\end{array}$ & $\begin{array}{c}\text { Very } \\
\text { Important }\end{array}$ & $\begin{array}{c}\text { Not } \\
\text { Important }\end{array}$ & $\begin{array}{c}\text { Somewhat } \\
\text { Important }\end{array}$ & $\begin{array}{c}\text { Very } \\
\text { Important }\end{array}$ \\
\hline $\begin{array}{l}\text { Overall job } \\
\text { satisfaction }\end{array}$ & - & $5(4.1)$ & $118(95.9)$ & $1(0.9)$ & $3(2.7)$ & $108(96.4)$ \\
\hline $\begin{array}{l}\text { Proper job } \\
\text { placement }\end{array}$ & - & $2(1.6)$ & $121(98.4)$ & - & $1(0.9)$ & $111(99.1)$ \\
\hline $\begin{array}{l}\text { Clear job } \\
\text { descriptions }\end{array}$ & - & $4(3.3)$ & $119(96.7)$ & - & $2(1.8)$ & $110(98.2)$ \\
\hline $\begin{array}{l}\text { Recognizing } \\
\text { and rewarding } \\
\text { good work }\end{array}$ & - & $3(2.4)$ & $120(97.6)$ & $1(0.9)$ & $1(0.9)$ & $110(98.2)$ \\
\hline $\begin{array}{l}\text { Supervisors care } \\
\text { about staff } \\
\text { and offer support }\end{array}$ & - & $5(4.1)$ & $118(95.9)$ & - & $5(4.5)$ & $107(95.5)$ \\
\hline $\begin{array}{l}\text { Regular staff } \\
\text { interaction } \\
\text { to improve staff } \\
\text { development }\end{array}$ & $1(0.8)$ & $8(6.5)$ & $114(92.7)$ & - & $1(0.9)$ & $111(99.1)$ \\
\hline Good morale & - & $3(2.4)$ & $120(97.6)$ & - & $1(0.9)$ & $111(99.1)$ \\
\hline $\begin{array}{l}\text { Each worker } \\
\text { valued, respected }\end{array}$ & - & $3(2.4)$ & $120(97.6)$ & - & $1(0.9)$ & $111(99.1)$ \\
\hline $\begin{array}{l}\text { Enjoyable, } \\
\text { stimulating } \\
\text { workplace }\end{array}$ & - & $3(2.4)$ & $120(97.6)$ & $1(0.9)$ & $1(0.9)$ & $110(98.2)$ \\
\hline $\begin{array}{l}\text { Training for job } \\
\text { success }\end{array}$ & - & $3(2.4)$ & $120(97.6)$ & - & $2(1.8)$ & $110(98.2)$ \\
\hline
\end{tabular}




\section{Qualitative Findings}

\section{Hiring Process}

\section{Participant Perceptions of the Hiring Process}

Participants in both states had mixed views about the fairness of the hiring process. In addition to hiring gaps, they cited procedural inconsistencies. There was consensus, however, that the hiring process is based on the civil service rule, which comprises: advertisement, application, shortlisting, interviews, selection, and employment based upon qualification and suitability. Hiring processes were perceived as loaded with challenges and bureaucracy slowing the process, and even halting it in some instances. Most participants who described their own hiring process reported it as fair and transparent, but felt it had progressively become more inconsistent and corrupt.

"The issue of hiring, there is inconsistency, yes, because it used to be...every set... admitted into school... will be put into the process, the process of employing...right from school. It used to be like that consistently, but as it is now, it's not every year you get it, because, like, the final year students that are in teaching hospital now, some of them the process of employing them started recently, while they were in their final year, which means there is a gap of two or three years...so it is not every year actually..."

Stakeholder, FGD, Bauchi

"Well the bureaucratic process it involves requires the advertisement of the vacancies and all that, and after that...it takes some time again - date for interviews, then after interviews, it takes a longer period again before people are informed who succeeded and then it takes some time again that they eventually have to report to fill documents, to do documentation. These things can take more than two months..."

Stakeholder, IDI, Cross River

\section{Means of Hiring}

The hiring process commences when needs and gaps are identified within ministries, and a memorandum about recruitment is prepared and sent to the governor; ministries are not empowered to hire without gubernatorial approval. When approvals are granted by the governor, they are forwarded to the civil service commission, for advertising, interview facilitation, and candidate selection. There are two routes for employment: one involving employment prior to nursing or medical school, which is then sponsored by the government for retaining; the other is direct employment of trained health workers from the state, or from without. The hiring process also involves testing health knowledge, literacy, and data interpretation. Some participants mentioned health workers who had been employed but could not perform basic tasks or write legibly.

"But for the hiring of junior officers, the Ministry or the Hospital Management Board or Primary Health Care Development Agency, it is the one that they will handle it. At times, they write straight to the Governor intimating him the shortages... they will write to Head of Civil Service, the Head of Civil Service will write to the Governor and seek for approval. But if approval is given, then they will send it to them..."

Stakeholder, IDI, Bauchi

"They are also supposed to check their ability to write, pick up data and understand data, because what we realized when we did the verification and audit, we found out that a lot of health workers do not know how to interpret data, so they just pick up data and they send it out but they don't know what it means.... We now found some few ones who could not even fill the verification forms by themselves...' Stakeholder, IDI, Cross River

\section{Experience with Hiring Process}

Participants reported a wide range of hiring experiences. Most described a rigorous, transparent process after response to an advertisement. Many participants were employed based upon merit, and a process, but some began as volunteers, formally employed after several years. A major route for employment is through school, as health workers funded by the government and appointed after completion of study. In all instances, however, a hiring process was reported. Sometimes there was a delay in completion, of months or years. Some participants found the process stressful. 
"During my own time, there wasn't any problem like political problem. I just applied by then, I learnt that Bauchi local government are looking for staff nurses. So, when I applied, they called me for interview and from there I was employed...But before employment, they told me that I may be posted to the rural areas. I said there is no problem. As far as I'm a midwife, I can serve any place and I'm here to serve the community. I was given permanent and pensionable appointment but when they took me from the beginning, I was given temporary appointment, after six months, they gave me permanent."

Manager, IDI, Bauchi

"I was employed in 2006 when I was in school and was sponsored by the Bauchi government. Immediately when we graduated they posted us to various health centers. They are giving us allowances, then after we served for at least three to five months, they gave us appointment as temporary appointment, then later on, after one year, they give us permanent appointment."

Manager, IDI, Bauchi

"It's 22 years now, government employed us, they trained us, we were not paying school fees, they were rather paying us, then after...immediately you bought their form, you go to entrance interview, they will give you appointment letter. In training they were paying us but now it's not like that..."

Health Worker, FGD, Cross River

\section{Considerations and Criteria for Hiring}

Bauchi and Cross River have clearly defined criteria for health worker hiring. Their processes are considered open because vacancies were advertised on radio and national newspapers, for qualified applicants. Interviews are conducted for all screened applicants, with results made available to the public. The hiring process commenced whenever there was a need for a cadre or specialty in a health sector after a thorough needs assessment of facilities, the workforce, and funding. A quota system is used in both states, with each LGA or senatorial district allotted fair representation in health system hiring. A quota system was not only reported for the hiring process, but in student admissions as well.

In some instances, gender, culture, and religion were also considered in hiring. Females were mostly considered in $\mathrm{MNCH}$ hiring, especially in Bauchi, due to cultural and religious reasons. Deviations were reported by many participants, however, who cited instances where financial inducement, political influence (political party affiliation or "godfathers"), or ethnic inclinations played a major role in health worker hiring.

\section{Availability of resources}

There was consensus in both states that resource availability was the basis for hiring decisions because budgetary allocation is crucial for actualizing recruitment decisions.

"It is based on the availability of resources. Even if we want five doctors, if there is nothing to accommodate them in the budget they will not be hired..." Stakeholder, IDI, Bauchi

\section{Competence and merit}

The need to recruit a competent health workforce led the constitution of committees for competencybased recruitment. There were, however, challenges in recruiting competent staff due to political interferences. Officials did their best to insist upon qualified candidates, regardless. There was consensus among participants in both states that politics played a role despite the commitment to a merit-based system.

Participants offered conflicting perceptions of the role of competence in recruitment, possibly due to individual experiences. Those employed based upon merit were more inclined to view the process as merit-based. Reported checks and balances included state personnel supervision of local hiring processes.

"This is a peculiar sector, and so they need specialist to be involved so that they don't make the mistake of engaging the wrong persons. And that is why they bring personnel, i.e. specialist from the ministry in the committee amongst them to carry out the selection. So, it is based on competence..." Stakeholder, IDI, Cross River 
"Of course, we normally stand on our feet. How do we employ someone that is not competent? We want him to go and kill people in the community, we would not be held responsible in the hereafter...Mind you, we normally tell them, frankly, you are going to be held responsible for your actions in the hereafter. How are we going to tell God that we employed somebody that is incompetent to carry out services?"

Stakeholder, IDI, Bauchi

"During the hiring of personnel, merit is strictly followed...in terms of professionals like doctors, pharmacists, even nurses..."

Stakeholder, IDI, Bauchi

The merit system was considered by some as complementing a quota system; meanwhile some respondents stated that less than a majority of staff were employed due to merit. A Cross River director indicated that 20 percent of any given recruitment was for merit-based applicants, and the rest to quotas.

"Assuming we want to employ one hundred nurses for the Ministry of Health and twenty out of the people invited for interview are top-ranking applicants and they are adjudged to be the best. Those twenty, we employ on merit irrespective of their local government...therefore, after the first 20, who are assumed merit positions, it's the balance of the 80 we now spread around the three senatorial districts. The first 20...they have those jobs strictly on merit."

Stakeholder, IDI, Cross River

The selection committee checks competence by verifying certificates and qualifications in addition to practical stratagems for participant demonstration of competence during the interview process. Dressing, eloquence, composure, response to questions, and practical scenarios are all assessed.

"One of the very important things I say is licensing, any Jack can get out and come up with a certificate, you send for verification...Verify!" [taps the table]. Stakeholder, IDI, Bauchi

"They should test the health worker's IQ, for example, if you are a CHEW you should be able to at least know how to write your name, spell malaria...but most of them, most of this staff I don't know where they get their certificate from...they are not very competent."

Stakeholder, IDI, Cross River

"But I'm not too sure whether they are really hired on competence. Because first of all, are they given exams? How do you assess their competence? Is it by just asking them questions and all that? Theoretical competence. Because health care is a technical thing....and since they are not set to test their practical ability, it means...beyond competence, some other factors could be used to hire..."

Stakeholder, IDI, Cross River

\section{Equal opportunity: Ethnicity, gender and quota system}

Participants' conversations about equal opportunity for employment in their states focused on ethnicity, gender, and other quota considerations. In Bauchi, there was a consensus that priority was given to state indigenes, but non-indigenes were also considered. Irrespective of religion, gender, and ethnicity, Bauchi was described as more focused on filling human resource gaps than on potential recruits' demographics. Several participants gave examples of non-indigenes in Bauchi who occupied top government positions.

"So even somebody from Enugu....you know we have non-indigenes working in Bauchi state, people from other states, as long as they went to school, they have the skills, they can do the work, they are qualified, we give them employment here...Up to the level of permanent secretary, Mr Victor has retired as a permanent secretary and he is from Benue state..."

Stakeholder, FGD, Bauchi

Everybody is giving equal opportunity. Particularly now with our emphasis on maternal and child health issue....we need more women."

Stakeholder, IDI, Bauchi

"I told you now we normally employ non-indigenes in the State in areas where there are no indigenes. [We have] an Igbo, a Christian working in Bauchi local government without any interference..."

Stakeholder, IDI, Bauchi 
In Cross River the situation is different. There is a default position that individuals not native to the state are not considered for employment. In instances where non-indigenes are working in the state, it was because there was a demonstrated need for an external individual for the role. There were more females in nursing, implying that nursing employment is skewed towards females. Within Cross River, there are mixed views about the role of ethnicity in employment. Some participants felt that LGA or place of origin were not used to discriminate during employment, but others felt that when political interference results in only people from the LGA or people of influence are employed. At the LGA level, only indigenes are employed unless there are no indigenes to fill the position. Respondents reported that it was easier for an indigene to work in his or her own LGA than a non-indigene.

"There are equal opportunities as regards gender but [for] some professions, some gender are more dominant, it's not because of the fault of anybody...for example, you look at nursing, males are given opportunity but if you advertise it's more women that will come and respond to that advert because they feel that it's more for women..." Stakeholder, IDI, Cross River

"There is this dichotomy of Atam and Efik. If an Efik man is at the head, the person will utilize the tendency of ethnicity. If Atam man is at the head, the Atam man will use the ethnicity tendency...That's how they divide us here. Whether we want to say the truth or not, I'm going to be objective." Manager, FGD, Cross River

"Yes, it is basically for those that are from the state, they don't hire people that are from another state... Since we don't take non-indigene, we don't hire non-indigene in the state."

Health Worker, IDI, Cross River

"It is easier, especially at the primary health care level...you must take into consideration ethnicity...if you employ somebody that comes from a particular community, the person will hold high responsibility... when you say, 'I am sending you to your community, go and save your people,' you have to take that into consideration...because if you send me to my community, I already have structures existing, I am not going to start looking for accommodation, and I can always get food from the farm..." Stakeholder, IDI, Cross River

\section{Corruption in the hiring process}

Participants from both states reported practices sometimes corrupting the hiring process. Competence is sometimes not considered, with employers soliciting payments to secure a position.

"Yes, in some aspects they turn to the highest bidder, sometimes they don't even consider competence, provided you can afford what they want..."

Stakeholder, IDI, Cross River

Respondent: "They will employ you if you have money."

Interviewer: "Do you mean that I have to pay in order to be employed?"

Respondent: "Yes, big time..."

Health Worker, FGD, Bauchi

\section{Gender issues}

Gender issues are due mainly to the proportionately lower numbers of women who apply, especially in Bauchi. It is culturally more acceptable for women in Bauchi to provide $\mathrm{MNCH}$ services, so they are given special consideration. In Cross River, qualified women are more available and apply more for nursing and midwifery positions. As nursing and midwifery are viewed as women's professions, they are dominated by women.

"The challenge is...female health workers...are mostly inadequate or somehow understaffed ...not enough to cover all the health facilities, to provide services that has to do with maternal health issues. So the government...even when they advertise...they give preference to the female workers, most especially the midwives...the nature of their work, and because of the culture and the tradition, we prefer the female to attend to the women, and, you know, almost 80 percent of our clients that visit facilities are women..." Stakeholder, FGD, Bauchi

"Well formerly, they were saying that nursing is for women and not for men...For every recruitment they do, there must be males...but still, females will still dominate..."

Stakeholder, IDI, Cross River 
"The preference they give to males is the same preference they give to females, as far as you have the qualifications of being employed."

\section{Need-based hiring}

Most participants reported that the hiring process is based upon identified needs within a health system. When manpower needs are identified, the recruitment process is initiated. There were mixed views, however, about the extent of political interference, with some asserting that it played no role in affecting identified needs, with others reporting that potential roles can be altered by officials in charge of recruitment.

"Because of the need...our needs assessment, then we call applicants for interviews."

Stakeholder, FGD, Bauchi

"As it happens nationwide, when there's a gap and there's need to fill the gap, the existing gap [will] be advertised, and that is what obtains in the state. There is....room for everybody to apply. Adverts will be published, and normally, now, it's not every Tom, Dick and Harry that will be employed."

Stakeholder, FGD, Cross River

"Well, before we hire or employ anyone into the service, we must be able to at least determine the manpower needs of each area and then recognize the gaps... We now do a small memo to the governor-the Ministry as presently constituted does not have power to hire anybody. The governor grants approval, and we forward it to the civil service commission, who does the advert...at the end of the day, the selection takes place and they are placed accordingly..."

Stakeholder, IDI, Cross River

\section{Political influence}

There was consensus that political interference is a major influence and factor in health worker hiring in both states. There are many factors of political influence, such as whether a candidate belongs to a certain political party. In some instances, only people with political affiliations have access to application forms and opportunities for interviews. There are possible repercussions for officials who refused to hire candidates with political affiliations or government connections.

"Political influence plays a major role, because, for example, when government intends to employ health workers...the commissioner will write a memo to his excellency with names of candidates requesting vacancy for employment, they will provide slots to commissioners, state assembly, top government officials. So, majority of employment of health workers are done by politicians. They rig and select..."

Stakeholder, FGD, Bauchi

"They will interfere because maybe both the Chairman or the Counsellor will say, tell them to be employed...yes, they don't care about their capability or their qualification...they are even sharing the quota..."

Stakeholder, IDI, Bauchi

"Yeah, it is still there, because of the political interference...how do I put it? Because you want to consider your own people, maybe you were given just three chances and those people that have the qualification are not given such opportunities."

Manager, FGD, Cross River

Political interference can extend to beyond the hiring process, making the individuals hired due to it beyond reproach, never queried or disciplined for infractions, due to their benefactors. In some instances, top government officials have the liberty to make appointments for individuals who are not qualified.

"I have a staff since February this year [who] I have not been seeing in the office, I process[ed] his file for a query [but] the file was returned to me without a comment. I resent the file, it came back to me without a comment. I took the file personally to my director, [when] I met him he said that somebody on the top who spoke to him [said] that it's his son and that he is using him to do some of his business, so doing the government job is not his problem now, so [for] almost six months now, he is receiving his salary every month." Stakeholder, IDI, Bauchi 
"Politicians have influence...if, let's say, originally, some high personalities have retired. And then you want to bring up people to fill up the cadre, you see that in most instances, the politicians will want to impose some people on you. They will send you some names they want you to use for their own community. They don't want another person from another local government to come there...So, that influence is there. Strongly there!"

Stakeholder, FGD, Cross River

"It has great influence on the persons hiring and who is hired and the consequence of not obeying some of the directives from some of the political leaders is great on the person hiring. But those persons may not be very competent. And in any case, those persons usually, even when they are competent, don't put in their best and are not subject to discipline. Because they always think there is somebody that protects them. And their work attitude is always very poor..."

Stakeholder, IDI, Cross River

\section{Quota system}

The aim of the quota system is to achieve equal LGA and regional representation within each state, for equitable development as well as fairness. The concept of catchment areas was about equity. The quota system sometimes does not work appropriately, however, due to political influences.

"Yes, we do consider catchment, you really have to make sure that every local government is represented, maybe that is what you can call political consideration, because we make sure that each local government is given a fair quota..."

Stakeholder, IDI, Bauchi

“That quota system usually doesn't work a lot or enough, I can say, because you can see some of the activity when they arise, it is those people that have somebody at the top, that will have a mega part of the activity."

Manager, IDI, Bauchi

Sometimes the quota system does not work appropriately due to scarcity of qualified professionals in some LGAs. In those instances, vacancies are filled from other LGAs. Some participants felt that population considerations are necessary to determine employment from each LGA. The quota system is viewed as promoting inclusivity, but it does not work for disciplines for which it is difficult to find qualified or specialized professionals.

"Yeah, the quota system should come to play...Etung has 10 wards, if they are doing employment in Etung, the employment should reflect the 10 wards, the candidate should be drawn from the 10 wards...a percentage [should be] given to the non-indigenes-you know there is a quota for that, about five percent, for non-indigenes, that should be followed."

Stakeholder, IDI, Cross River

"In Cross River state we have 18 LGAs. If the state government advertise for job, the chairman of the Civil Service Commission, the man is very meticulous, they will check, local government by local government. If they are sharing three-three...depending on the size of the LGA, too, they share. But in a situation where a particular LGA cannot meet up [with] the target that they want from there, that's when they look outside."

Manager, FGD, Cross River

"It depends on the calibre of persons they employ. For doctors, because they don't even have those that want to come so, sometimes...the quota system doesn't play so much role. But when there are enough doctors coming from different local government area...they surely apply the quota system."

Stakeholder, IDI, Cross River

\section{Transparency}

Key elements of transparency described by participants include: civil service commission advertisements of position openings, interviews of shortlisted candidates, and publishing results of interviews.

"I can also say that it is transparent in the sense that this thing will be advertised, and they will be interviewed, and the result is also going to be pasted for the public to see, so I think there is transparency in that respect."

Stakeholder, IDI, Bauchi 
"Maybe not 100 percent, because equal opportunity is given to everybody that applies...you are going to be invited for interview, unless if there is a prior screening and they find that you are not qualified. And then the result of the interview is published, and you are invited to accept the offer or to reject the offer. So, to that extent, yes. But of course, we cannot claim that it is 100 percent right. There will certainly [be] issues of favoritism or something like will not be based totally on merit."

Stakeholder, FGD, Cross River

\section{Rating the hiring process}

Participants were asked to grade the hiring process in Bauchi and Cross River, with a wide range of responses, from 20 percent to 80 percent. Ratings as low as 20 percent were given by participants because of challenges such as high unemployment, shortages of manpower within the health system, and lack of equipment and facilities in both states. Participants who gave higher ratings felt that both states had done much over the years, but needed to do more in hiring health workers.

"If it is according to my community, I can say 30 percent, because we have a lot of graduates around and we have overloaded our facility. There is a lack of manpower, so, and there is no employment from the state, so to me it is 30 percent, if that the state tries to employ about 200 or 300 health workers then I will give them more than that, we have many graduates in the state and they are not working..."

Health Worker, FGD, Bauchi

"Ma, I will say four over ten which is poor, the reason is because, they've not been employing and then so many are out there that have this qualification...that is why I score it that way 'cos presently in this facility as a whole we have only three nurses in Odukpani, the rest are offshore, but there are other nurses out there that have graduated, maybe looking for job and they've not had, same for other tertiary institution... and that is why I am grading four over 10, please the government should employ." Health Worker, IDI, Cross River

\section{Challenges in the hiring process}

\section{Discrimination and political influence}

Some participants complained that some vacancies were not announced and filled secretly, to reduce the chances of a wide range of applicants. Sometimes information about employment opportunities are only conveyed by word of mouth, to those targeted for the job. This situation, described by some participants, was mainly used by top government officials to recruit their children into the health workforce. Lack of employment and limited opportunities are considered reasons why politicians secure these limited opportunities for their family members.

The concept of "godfatherism" refers to employment facilitated by a politician or government officials. Some individuals are oblivious of its impact on health outcomes, if poorly qualified people are employed instead of those who are qualified. In a few instances, after employment of qualified candidates were finalized, a counter directive was issued to employ someone who was not part of the interview process.

"If they want to employ people they don't normally announce, they do it secretly and they only take their own children to employ, because I can remember there are many people that have graduated, they are sitting there, they have nothing doing, so if they want to employ people, they only call their brothers...they do discriminate even though you go there for the interview they will not employ you..."

Health Manager, IDI, Bauchi

“They asked me, 'Don't you have a godfather?' I said, 'What sort of godfather?' I remembered I was shedding tears....right there in teaching hospital. I said, 'Godfather?'...'Your geographical area, don't you have a senator?' I said, 'but I got my paper, and I'm here for the interview'...So, because of 'godfatherism' [sometimes] you don't even have the qualification to practice as a health provider in the field, but you are given employment." Manager, FGD, Cross River 


\section{Employment embargo}

Many study participants referred to an embargo on employment in both Bauchi and Cross River due to financial constraints. Embargos on employment are not limited to the health sector. A large proportion of health workers are providing volunteer services and are not sure when they will be formally employed. With health workers regularly retiring, the embargo on hiring has significantly affected health care delivery in both states. A waiver was issued in Bauchi, for nurses to continue service for three years after legal retirement. Lifting the embargo is contingent upon improvements in the states' financial situations.

"Since 2012 till now, no employment, even next year we are not sure if they will employ and since that 2012 till now, people are retiring day by day..." Health Worker, FGD, Cross River

"I think at least for almost four years...since 2014, the government placed an embargo [on employment]... when there was a change in government, the government came to review, to see the position of their financial status, so they put an embargo on many things including hiring in the state..." Stakeholder, FGD, Bauchi

"Because so many health workers have retired, and the spaces are there, nobody to fill the gap....you discover that the PHC Coordinator will go and hire outside...because there are no health workers...These ones are volunteers and they are not technical staff...there are gaps in the health sector. Many people have retired."

Stakeholder, FGD, Cross River

\section{Poor funding for the health sector}

States' inabilities to pay health worker salaries is considered a challenge to hiring not only because of its immediate effects of attrition, but it makes it more difficult to attract competent personnel.

"I don't know why they are not employing. I feel there is no money. That is what I feel..."

Manager, IDI, Cross River

"Yes! Money, materials, and manpower, you may get the materials and the manpower, [but] you may not have the money...that is what is lacking." Stakeholder, IDI, Bauchi

"At the moment, Cross River state doesn't benefit from the oil boom in this country, but we are within the oil-producing state. So, that is why the government is crying for funds to manage a big department like Health. The government is not employing...you go to some health facilities, you see only one staff. In the PHC, two. How can they cope up with the teeming population? You know that is one of the major barriers...we don't have money like other states, according to what the governor told us..."

Stakeholder, FGD, Cross River

\section{Corruption}

Corruption, in terms of applicants paying officials (bribing them) for employment is viewed by respondents as a challenge within the hiring process, sometimes resulting in incompetent health workers.

"Years back, when Ministry of Health was about to employ health workers, for example, if director's approval was given for them to employ 1,000 , they will add...20 or 200 , to collect money from candidates...if you pay so so amount, I will give you the job..."

Stakeholder, FGD, Bauchi

"Sometimes, they used to give 40,000 Naira, 50,000 Naira, or something like that, to be employed..."

Health Worker, FGD, Bauchi 


\section{Hiring Policies and Guidelines}

\section{Awareness of policies}

Most respondents, from both states, were familiar with civil service rules, which provide some hiring guidance. Respondents appeared vaguely aware of procedures but were uncertain about periodic reviews. Some participants who were aware of the civil service procedures reported that they did not seem to result in positive changes in hiring and recruitment of health workers in their states.

"There are civil service regulations, and there are criteria for employment in it."

Stakeholder, IDI, Bauchi

"There are no guidelines, to the best of my knowledge...We requested...at least...300 nurses for three to five consecutive years...[to] address the gaps...there is no laid down rule that you will be recruiting as people are exiting...if it had been, this problem of manpower shortage, wouldn't have been there...these exits are not replaced..."

Stakeholder, IDI, Cross River

"I think, there is a guideline on hiring...I don't know if those guidelines are working...there is no money and people are not being employed. But I think there is a guideline. The civil service [rule] is there and the human resource for health policy...they have launched it here..."

Stakeholder, IDI, Cross River

\section{Documentation and Scope of Policies and Guidelines}

Hiring procedures are reportedly well documented, covering a range of matters including deployment and promotion. Most respondents do not have copies of the relevant documents, and those who have copies have not read them fully, due to poor dissemination or a poor information culture in general. Some health workers close to retirement had not seen nor read of any procedures for health worker hiring. Most participants with copies of the civil service rules are higher cadre health workers.

“I own [the Civil Service Rules book], but I don't know everything about it, I know some..." Stakeholder, IDI, Bauchi

"I have not read any one, we used to hear about it from our staff officer...The civil service rule is usually used, according to my understanding, to control the staff...if you are working as a staff you should follow all the rules and regulations...." Health Manager, IDI, Bauchi

"We have not heard anything about it. At least we have not yet seen it..."

Health Manager, FGD, Cross River

"Yes, somebody told me that there is a booklet that you can read to know what and what is obtainable concerning hiring, even ethics, dismissal or whatever...but I have not seen it, so I cannot really say much about it." Health Manager, FGD, Cross River

\section{Implementation of Hiring Policies}

The widely held perception among health workers is that hiring policies are not being implemented, or followed as prescribed. Although the civil service rule is viewed as a binding document and guiding principle for government civil service, hiring processes do not appear to always follow it. Participants were asked to rate the implementation of hiring policies, with most respondents opining that it was poor and provided only theoretical guidance.

"It serves as a guide and it gives you the power to do your work and you will carry out your work dedicatedly..." Stakeholder, IDI, Bauchi

"It's not functioning...it's not applied." Stakeholder, FGD, Bauchi

"Civil service rules definitely are playing a key role in employment within the civil service...but I cannot say 100 percent, as of now, because civil service sincerely is in shambles, so I can't say 100 percent, let's give it, maybe, 70 or 80 percent." Stakeholder, IDI, Bauchi

"They are not following it. They are not doing it." Health Worker, FGD, Cross River

"No. No, it's in theory." Health Manager, FGD, Cross River 


\section{Barriers to Implementation}

Political influence and poor funding are viewed as major barriers to implementing official hiring policies. Other barriers reported by respondents include local culture, corruption, favoritism, ethnicity, and limited information access. Poor access to information among prospective health workers in rural areas was viewed as a barrier to implementing hiring policies because they usually did not hear about vacancy advertisements. Even in instances where there was some commitment to following the civil service rule for publishing advertisements, before they were published top government officials had notified their preferred candidates to apply. Eligible candidates in rural areas barely hear about employment opportunities. Although policies were designed to promote equity in the hiring process, policy implementation does not reflect it.

"The weakness, as they say, is political. Secondly, funding...that I cannot defend because government will always tell you they don't have funds..." Stakeholder, IDI, Cross River

"We have obstacles like interest of political office holders. The employers themselves, influencing the process...the remuneration is not good enough." Stakeholder, IDI, Bauchi

"Politics! because now, despite the fact that the government knows that there are gaps in human resources for health, if they are given the opportunity to employ, they will not employ the skilled, they will go and employ the non-skilled...they will just employ family and friends."

Stakeholder, FGD, Bauchi

\section{Deployment of Health Workers}

\section{Factors Affecting Worker Decisions}

\section{Acceptance of postings}

Participant accounts emphasized factors that influence the acceptance of postings by health workers, which include:

- A conducive working environment

- Work incentives, and

- Health workers' commitment and passion for the profession.

"If you have a good working facility, you'll like to be in that place..."

Health Worker, FGD, Cross River

"There was a time people didn't want to go to the rural areas, like I earlier told you. So, government brought in the issue of rural allowance. And that tended to help make some people want to go to some rural places so that their pay package would be better."

Stakeholder, IDI, Cross River

"Well, somebody like me, I don't reject posting. Anywhere they posted me to, I go."

Health Manager, IDI, Bauchi

\section{Rejection of postings}

Participant accounts emphasize factors that influence rejection of postings by health workers:

- Personal circumstances, such as further studies or health issues

- Lack of social amenities including accommodation

- Financial issues: cost of living and remuneration

- Community acceptance or rejection

- Family concerns: separation from family, schooling for children, and

- State of health care facilities, including security issues, remote locations, among others. 


\section{Personal circumstances: Further studies or health issues}

Sometimes personal circumstances made it difficult for people to accept postings. The need to further education or health issues may result in rejections of rural postings.

"Yes, almost everybody wants to come to Calabar [state capital]. Some of them want to go to school, because there are times they are given admissions and they are granted some leave, and they want to stay here in Calabar. Some of them are doing part time while they are still working."

Stakeholder, IDI, Cross River

"Staff should only reject posting based on health grounds. That one is considered, if a staff's health is failing, then he rejects the posting, you the policymaker [should] look into it. Then, you can now re-post that staff to where it will suit the staff because of the health of that staff." Health Manager, IDI, Cross River

\section{Lack of social amenities and accommodation}

The availability of accommodation was considered an important incentive in accepting or rejecting rural postings. Basic amenities such as water, electricity, and communication are considered crucial in attracting health personnel to rural areas. Some health workers prefer urban areas because the availability of amenities makes it easy to run businesses in addition to official work.

"When you see where they stay, it's not fit...so, it kinds of makes people reject rural posting, so if in the rural areas, there are befitting accommodations with some little amenities such as water and light, I don't think anybody will reject working in the rural area."

Stakeholder, FGD, Bauchi

"Because when you get to a place, you have been posted there, you may be willing to work. If there is no proper accommodation...to make you feel at home, it may make you to go back, to be reposted out."

Stakeholder, FGD, Cross River

\section{Financial issues: Cost of living and remuneration issues}

There was consensus among participants that it is more expensive for families to live apart, especially when remuneration is poor, and it is more difficult when a family member lives in an urban center, where cost of living is higher. The rural posting allowance was instituted as an incentive to motivate deployed staff to remain in rural areas. In instances where the rural allowance is not paid, deployment to rural areas was considered unattractive by participants.

"The difficulty of living is one. If a health worker is on a salary of 30,000 Naira. For example, he has a wife, probably one or two children... He will find it difficult to come and live in the city and cope...the next thing is for him to decide, please, post me to where my family is and let me live with them. He [then] cuts costs...."

Stakeholder, IDI, Cross River

"This rural allowance was introduced to entice people to opt for more rural posting so that we will retain manpower at the frontline and try to improve health care delivery system at primary health centres. Sometimes you find out that you have complaints from the health workers that the amount is too small..." Stakeholder, IDI, Bauchi

\section{Community acceptance or rejection}

Some participants reported that communities usually did not want to release health workers who have been committed to serving them. Such communities consequently reject any attempt by the ministry to re-deploy local health workers and replace them with new personnel.

"We have some staff that we wanted to take to another place, but the community protested that they want this person to remain, because they are enjoying the services...sometimes even the health workers themselves, some of them have negative attitude, when you send them, the community will reject them...so we do have that kind of thing, it does happen."

Stakeholder, IDI, Bauchi 
Family concerns: Separation of families and children's schooling

Health worker deployment sometimes separates newly wedded couples or families, or negatively affects their children's schooling. Health workers may consider the costs and benefits of a posting.

"If you are a newly wedded couple and then your job is carrying you away from your husband, for over two years or one year a man doesn't see you pregnant for him, it will seem as if he has made a mistake by picking you as a wife..." Health Manager, FGD, Cross River

“...their family is in an urban area, so they don't want to go to a rural area...even if the area is their own local government they will reject it." Stakeholder, FGD, Bauchi

"Some will say I am married; my husband is in Bauchi, how can I go to a village and stay? My husband has one wife and we have children. Who will take care of the children? Who takes them to school? We have such kind of cases..." Stakeholder, IDI, Bauchi

"They will not want to go because of their children who are in school, because some good schools may not be in the place they are posted to..."

Stakeholder, FGD, Cross River

\section{State of the health care facility: Security issues and remote areas}

Security concerns and challenges with access were common reasons for rejection of posting. Some health care facilities are in remote areas and difficult to access during rainy seasons. With little or no provision for staff safety and security, some health workers are forced to reject postings in remote areas. Security challenges are also considered reasons why health workers reject postings, especially in Cross River. There were accounts of health workers being kidnapped, bitten by snakes, or attacked. Some participants complained that most facilities in rural areas are dilapidated, poorly equipped, and poorly maintained, not considered conducive for either patients or health workers. Some facilities are even non-functional, with staff made redundant because patients have stopped presenting there.

"In Abi local government area, there is a bridge...being constructed...initially we go on boat or speed boat, so during the raining season they send people there on transfer, those...not used to water...they don't know how to swim, and there is no life jacket for them, sometimes we record water accident and we lose some staff." Health Manager, FGD, Cross River

"They are hard to reach...even to find a means of going there is a problem..."

Stakeholder, IDI, Bauchi

"And like that local government...that you will trek two days before going to that place to work, or to stay there...you can't even come out. Going there you find out that if they deploy somebody to go to that type of a place, he will not be able to go..."

Stakeholder, FGD, Cross River

"The major thing is security, they want to know that, that community you are sending them to, they will be secured, if not, even if you pay them one billion they won't go because they have to be alive to eat that money..." Stakeholder, IDI, Cross River

\section{General Considerations for Posting Health Workers}

Participants mentioned general considerations for health worker postings:

- Worker's gender

- Worker's health condition

- Security and conflict issues

- Personal requests and family concerns

- Number of years at a facility, and

- Deployment posting rules 
Cultural preferences for women to conduct deliveries makes gender a consideration for posting, especially in Bauchi. In accordance with civil service rules, poor health status is also a key consideration in health worker deployment. The number of years a health worker has spent at a posting is sometimes a consideration, for varied health system experience.

\section{Gender}

"If you say gender, I will agree with that, because of the sensitivity of culture and religion in the state, especially to do with antenatal care and hospital deliveries. Most communities prefer women in their area, so even if you don't have women in that facility they will even come to you and demand that you send a female worker to them." Stakeholder, IDI, Bauchi

\section{Health Condition}

"Sometimes transfers are considered because of health, if they transfer you...It is you that will come back and tell them that, look at what I am passing through...before they will listen to you, consider... where you will be able to work."

Health Worker, FGD, Cross River

\section{Security and Conflict}

"Because of some other issues like this Boko Haram that came, you know if he's fearing, obviously he will not stay there, so he'll request to be transferred to other places."

Stakeholder, IDI, Bauchi

Personal Requests and Family Concerns

"They do consider cases like pregnancy and distance marriages. For instance, if your husband is being posted to another LGA, and you are here..." Health Worker, FGD, Cross River

Skills and Relevance of Health Worker

"We also consider the skill of the health worker and their ability to function well in that environment..."

Stakeholder, IDI, Cross River

Number of Years at a Facility

"If you have stayed in a particular LGA for a certain number of years, you will be moved to go to another LGA to have experience [there], that it is a kind of general rotation..."

Health Manager, FGD, Cross River

\section{Need-based posting}

One of the most important criteria for health worker posting is facility need, based upon service delivery and size or type of facility. Based upon patient load and data, staffing gaps are identified, the SPHCDA director and HRH coordinator are informed, who then facilitate the posting process.

"We consider where the need is, and so if there is a facility and the number of people who live in that community will be served by that facility, the utilization and all that are considered...we also consider the skill of the health worker and their ability to function well in that environment." Stakeholder, IDI, Cross River

"The local government makes decision where to post their staff based on needs, population, size of facility, services they provide, because you cannot post service providers to where their work is not needed..." Stakeholder, FGD, Bauchi

\section{Rating the Deployment Process}

Respondents were asked to rate their state's deployment process based upon their perception of its adherence, and whether needs are identified before deployments. Most health workers in both states rated the process below average, because, according to them, most health centers endure staff shortages, dilapidated facilities, and poor service conditions. Those who rated the deployment process average stated that the government had been intervening by paying deployed workers their rural allowances, although the process is still considered politically influenced. Those who rated the process above average did so because they felt the posting rules were followed strictly. 
"Let me say 50 percent, because, with the intervention of this government...there are some allowances, that if you are posted to rural areas you will get, while if you are posted to urban areas you will not...so...I will give this 50 percent."

Health Manager, IDI, Bauchi

"I score it poor, because [like] I said, most people don't want to go to the rural areas, where the facility lacks staff...go to the rural area, you find a facility that, there is no watchman. The CHEWs, the JCHEWs is the one that will sweep it, he's the cleaner, he's the card issuer, he's the doctor, he's everything there."

Stakeholder, IDI, Bauchi

\section{Issues with Deployment}

\section{Lobbying for postings}

All participants reported that lobbying for job postings was common practice in the Nigerian civil service. This commonly results in inequities within the system because others are shifted to accommodate a health worker's preference for a specific job or location.

"They do lobby to go to certain places of their convenience..."

Stakeholder, IDI, Bauchi

"Some people know that transfer is coming out from the pharmacy, they will now go and meet their people, lobby and they still remain in that particular place..."

Stakeholder, FGD, Cross River

\section{Payment of allowances}

There were mixed accounts of deployment (e.g. rural posting) allowance payments. While some participants reported not receiving their allowances, others had received them, or knew of others receiving them. Others reported that the government used to pay workers, but had now stopped. The uncertainties surrounding the payment of rural allowances and lack of understanding of the structure of health worker payment was a discouraging factor for rural postings.

"Yes...I'm collecting rural posting allowance...I'm still collecting... It's adequate because there are differences, even in salary. People working in the rural areas, [their] salary differs from...urban areas because of this rural allowance..." Health Manager, IDI, Bauchi

\section{"Before we were implementing [rural posting allowance] but now it is cut off!"}

Stakeholder, IDI, Bauchi

"I'm not very conversant with the issue of rural allowance, whether it is paid to health workers or not. But what I know is call duty in the rural area, it becomes like a stable allowance that must be paid..."

Stakeholder, IDI, Cross River

"There are places we have designated as rural areas and any of our health worker who is sent there is given rural allowance as much as possible." Stakeholder, IDI, Cross River

There were mixed views in Bauchi about rural allowance payments. While some reported receiving them, others were unsure of the salary structure and different components of their payslip. There was consensus among Bauchi participants that the rural allowance had been suspended in the past, but not for whether the allowances were reinstated. One Bauchi participant commented that other allowances such as a transportation allowance had to be requested, and that the payment was not automatic. Other allowances such as shift allowance were also not regular. A rural allowance is only paid for a posting to an applicable location, and is stopped once a health worker is posted to an unlisted location.

"If you request and follow up maybe they will pay, but it is not a policy. You will fill the form, then forward this to the authority so that approval will be given..." Stakeholder, FGD, Bauchi

"Government are giving the allowances, all the allowances are intact...everybody is collecting the allowances. There are rural posting allowances...shift allowances...call duty allowances, but only those that are working in the office don't have any allowances, like me..."

Stakeholder, IDI, Bauchi 


\section{Consequences and Disciplinary Measures for Posting Non-Compliance}

Most participants indicated that non-compliance with postings is regarded as gross misconduct, which can lead to health worker dismissal. Disciplinary measures follow the civil service rules: $A$ health worker first receives a written query, and if $\mathrm{s} /$ he still does not comply with a posting, salary is suspended, with his/her name deleted from the payroll. Some participants said disciplinary measures are not always enforced because some non-compliant health workers have "godfathers" in the system and are regarded as 'untouchable'.

“...refusal to [take up] posting is a serious misconduct, it could lead to dismissal...”

Stakeholder, FGD, Bauchi

"In normal circumstances, if there is nothing wrong with you and they post you to a station, if you say you are not going, then they stop your salary. They cannot pay you when you are not working, because immediately posting is done, you are supposed to begin in your facility and start work..."

Health Manager, IDI, Cross River

"Disciplinary measures are not working... when you give the query letter he answers and it is put in his file, sometimes someone will go and remove it. You cannot even see it..."

Stakeholder, IDI, Bauchi

\section{Retention of Health Workers}

\section{Discouraging Factors}

Factors that reduced health workers' motivation in both Bauchi and Cross River and affect their retention include poor working conditions, lack of promotion possibility, and staff shortages. Staffing shortages are significant because they increase current staff workloads. Financial issues such as delays in salary payments, arrears, lack of opportunities for capacity-building, and poor retirement benefits and allowances were also seen as de-motivating factors. Factors mentioned during interviews include:

- Poor remuneration and general financial issues

- Compulsory retirement

- Poor working conditions

- Lack of training

- Lack of adequate supervision

- Shortage of staff

- Lack of promotion, and

- Lack of basic social amenities.

"But there are other factors to do with equipment, work environment even the condition of the facility...you cannot work in a facility that is leaking all over and expect that person to be as happy as someone that is in a very conducive environment..." Stakeholder, IDI, Bauchi

"If your salary comes as much as you want, there is a tendency to get motivated, [sometimes] your salary will not even come on time..." Health Worker, FGD, Bauchi

"Some of us have been promoted over seven years now and nothing has been done and even when we have to even go for further training to enhance yourself and come back...no appreciation is shown...people get promoted [but] no arrears..."

Health Worker, IDI, Cross River

“...like in my own facility, no basic amenities, no water, no light..."

Health Worker, FGD, Cross River 


\section{Motivating Factors}

A personal commitment to saving lives was reported an important motivating factor for remaining in the health system. Other motivating factors, such as training, timely payment of retirement benefits, work incentives, adequate manpower, and conducive work environment, mentioned are aspirational due to the fact they are currently not manifest. Appreciable motivating factors mentioned were:

- Incentives

- On the job training and capacity building from NGOs and partners

- Passion for the profession

- Supportive supervision.

"Sometimes my motivation is just from NGOs, sometimes NGOs are working in collaboration with the government, they call you for workshop and train you, improve your capacity and make you happier, if not, I don't think there is any other motivation from the government..."

Health Worker, IDI, Cross River

"For those persons that retire if they pay them their pension and gratuity on time, it will motivate those of us that are working to really give our best because knowing that at the end, we will be given what is due [to us], It will really motivate us to do our best."

Health Manager, FGD, Cross River

"There should be a medical doctor posted down here, so that even if the person is coming twice in a week...there are some cases that we will not be able to handle...we can also call him on phone..."

Health Worker, IDI, Cross River

\section{Bonding and Hiring Process}

\section{Bonding practices}

Bonding practices are similar in both Bauchi and Cross River, playing an important role in health worker motivation and retention. Those who want to be sponsored at health training institutions by a state government sign a bond before commencing training that requires service for the state for a stipulated period after graduation. Most respondents report that bonding helps to address staffing shortages and unemployment challenges in the states. Respondents had concerns about the Ministry of Health's commitment to holding defaulters accountable.

"You know, in Bauchi state generally, we have a shortage of manpower...so the state actually made this policy in order to cushion that effect...so that when the health workers are in schools we pay them salaries and bond them, when they finish they come back and then do some number of years for us before they leave...and it's working because recently we really stepped up the enforcement of this bonding on the signatories." Stakeholder, IDI, Bauchi

"For bonding, when government trains you and you come back you have to stay for at least two years...before you are free...so bonding has been existing in the civil service and the only thing is that one needs to enforce it and follow up." Stakeholder, IDI, Cross River

"I know there should be a penalty for failing to serve the bond...I know that there are some doctors who were called back from where they are, because when they came back, they went to some other organization to serve that is not within the state...they either come back or they refund what was spent on them during the training." Stakeholder, FGD, Bauchi

\section{Bonding challenges}

Challenges in the bonding policy, and its implementation, mentioned include:

- Lack of policy implementation to deal with defaulters

- Lack of incentives to retain bonded employees

- Lack of monitoring systems to track bonded employees

- Lack of capacity-building for ongoing professional development, and

- Lack of health worker commitment to bonding provisions and agreements. 
"If you are employed through the school, you will sign a bond...to serve for the period of the bond, but some do run away...the government may not even know they have ran away...until after some years..."

Stakeholder, FGD, Bauchi

"The difference in remuneration...if you go to our neighbouring state you may find out that their salaries are better than this. Also, they are paying gratuity after leaving service. So most of the people leave from Bauchi to other states." Stakeholder, IDI, Bauchi

"But even the bonding, I don't think the government is implementing the bonding effectively because people still come, they are bonded yes, but they still leave."

Stakeholder, IDI, Cross River

\section{Task Shifting Policy}

Awareness of task shifting policy

Health workers were trained for tasks not primarily part of their health facility responsibilities. Most respondents from Bauchi and Cross River were aware of their states' task shifting policies.

"Yeah, that task shifting policy is just the same [with] what we are saying...nurses, midwives were trained to carry out ultrasound. CHEWs were trained to carry out the work of a midwife, all these ones are task shifting." Stakeholder, FGD, Cross River

\section{Effect of task shifting policy on workers}

Respondents believe task shifting has offered them the opportunity to be trained in other important aspects of health care. The effects of task shifting, as identified, include improved staff motivation, improved worker capacities, increased quality of service delivery, and reduced effects of staff shortage, in both Bauchi and Cross River.

"We do the delivery and we do the cleaning, pharmacy dispensing...Yes, more work motivates me, and it has really made me to be up and doing. I have to do this thing, because there's nobody to do it, so, I must learn how to do it...it has motivated me to perform well..."

Health Manager, IDI, Cross River

"Community health extension workers are being trained to do the work of the midwives and without them I'm sure we will close so many of our facilities because the midwives are not enough, and people have to deliver..."

Stakeholder, IDI, Bauchi

"Of course, yes, it's a motivation. When they give them this MLSS training...they have the knowledge of midwives they will use that knowledge to help people in the community."

Health Manager, IDI, Bauchi 


\section{Discussion}

\section{Hiring Practices and Procedures in the State}

This study establishes that there are gaps in both implementation and adherence to the processes for recruiting health workers established by the civil service commissions of both Bauchi and Cross River states. The study revealed inconsistencies in advertising of position vacancies, reported by respondents from Bauchi, and in Cross River, where most vacancies were advertised, often a large proportion of respondents did not see the advertisements. This finding supports qualitative accounts of poor dissemination of information about job opportunities, with most advertisements closing before prospective applicants have a chance to view them.

There are gaps in awareness of the policies and procedures for hiring, among both health managers and policymakers implementing the policies, in both states. Policy awareness is crucial to ensure implementation can be tracked, with policy reviews to ensure strategies are both current and relevant for a growing workforce. Consistent with the opinions of most FLHWs, most health managers believe both states' hiring process to be based upon merit.

The quota system was designed to ensure representation for LGAs and regions within each state, to contribute to equitable development of each region. Key issues in the interviews included lack of qualified manpower from certain regions and political influences that significantly limit the quota system's proper implementation. Striking a balance to ensure a competent workforce within the mandates of a quota system requires implementation that is transparent, with clear processes for addressing shortfalls, to avoid the marginalization of certain groups. For disciplines with critical shortages, the need to recruit competent professionals should override the quota system. Merit should be at the core of the quota system, regardless. Other considerations such as acceptance of health workers within host communities are important.

Poor adherence to hiring processes significantly affects workforce quality and does not promote equity in recruitment. A health worker hiring program in Kenya limited its process to three months and improved its efficiency through strengthened human resource management systems, with support from the private sector. ${ }^{19}$ Engaging the private sector in the hiring process has been identified as a potential strategy for improving HRH management systems. ${ }^{20}$

In both states, the most common means of advertising job vacancies is radio, due to its potential to reach a wide audience, especially in rural areas that may lack access to television, newspapers, and government office advertisement boards. Reliance on word-of-mouth for vacancy notification was an important finding in this study. This informal, unpredictable approach not only clouds but complicates the transparency of the recruitment process. Information transmitted informally or word-of-mouth can easily be miscommunicated and undercuts the goals of equal opportunity for applicants. The persistence of informal channels results in the hoarding of information and privileging access for potential applicants affiliated with top government officials or politicians. Another key problem raised in interviews was demands of payments or bribes by hiring managers from applicants.

In addition to the means of advertising, provision of adequate information about the position and its cadre is important. In both states, the most common mode of job application is in hard copy (typed or handwritten) instead of online. This may have some advantage by fostering inclusivity for applicants with limited internet access. The online application system clearly has increased merit in the long term; it can be adapted with a user-friendly interface, enhanced data storage, and means of improved processing and transparency. Online advertising may also lower costs and increase efficiency, as governments can creates database of aspiring health workers in their state. In Bauchi, candidates primarily hear about interview dates via informal channels such as word-of-mouth, but the use of text message prompts and noticeboards in Cross River provide better reach of potential candidates, given the high level of mobile phone penetration in Nigeria. Gaps in each state's mechanisms can be addressed by using multiple notification techniques to ensure no candidates are excluded from critical information exchanges. 
Although staff orientation exercises are conducted for newly hired workers, they do not include clear job descriptions. Provision of job descriptions reduces confusion and conflict of roles and work, and enhances performance. The HRH strategic framework (2008-2012) recommends induction and orientation for new health sector employees within three months of appointment. ${ }^{20}$ Staff orientation exercises should incorporate job descriptions; absent this, the roles of new health workers are merely assumed, by all parties, and jeopardizes health care standards. The task shifting policy cannot be effectively or safely implemented without clear and public definitions of tasks of each and every staff member and cadre. Furthermore, most health workers in both states did not receive a service schematic or staff manual. This implies general lack of awareness of key issues, including their job expectations, rules of client engagement, benefits, or consequences of misconduct. These issues directly influence staff motivation and job satisfaction.

A few health workers believed the HRH hiring process discriminates in terms of gender, reported to a large extent in Bauchi, where it is more culturally acceptable for women to provide $\mathrm{MNCH}$ services. Unfortunately, there are few women available to for nursing careers in Bauchi. The Bauchi government may need to create initiatives to attract and retain women for its health workforce.

An embargo on recruitment in Bauchi and Cross River has reportedly been in place for three and six years, respectively, due to financial constraints. These embargoes result in aging health workforces and lack of capacity to replace retiring staff, and deprives states opportunities to attract young talent. An aging workforce can affect productivity and staff knowledge of current best practices. Although the waiver in Bauchi, that enabled nurses to work for three years after retirement, is laudable, it is only a temporary measure for a critical problem threatening health care development in both states.

There is consensus that hiring processes are based upon identified needs in the health care system, and this is considered best practice. ${ }^{21}$ It is unclear, however, if the needs identified are data-driven, evidence-based, or upon subjective appraisals of decision-makers. Barriers to implementing a needbased recruitment strategy that were emphasized in interviews include poor funding and political interference, with top officials including candidates not recruited in official processes. Views shared about the hiring process, advertisements, interview process, and recruitment are similar, with the general perception of increasing corruption and inconsistency. Political interference was mentioned throughout the qualitative interviews as a major barrier to effective hiring of a competent health workforce, in both states.

\section{Deployment of Health Workers}

Awareness of deployment policies is low, and FLHWs are dissatisfied with the deployment process. Low levels of satisfaction are linked to poor planning and a range of issues including lack of amenities at facilities and problems with workers' accommodations, remuneration, family separation, and security concerns. Family separation hindered compliance with rural deployment, particularly in Bauchi. A study of retention factors in Ogun state revealed relocation of 17.5 percent of health workers from rural to urban areas due to marital reasons. ${ }^{22}$ Challenges with rural settlement include insufficient basic amenities, allowances, and a conducive work environment, which exacerbate the inconvenience of acceptance and increase inclinations for rejecting rural postings. Rejection of rural postings creates critical health system issues because FLHWs are most needed in those areas.

In some instances where FLHWs were posted to non-functional health facilities, staff was redundant because patients had stopped presenting at those facilities. A comprehensive audit of health facilities is needed to ensure basic infrastructure to support deployed health workers. The security and safety of FLHWs should be a primary consideration for staff posted to remote areas or areas with security issues.

Although more than half of health managers reported that their states redistribute staff based upon workload projection (i.e. need-based), nearly the same proportion believe workers are poorly distributed among the different levels of care. Findings from this study show gender is a key consideration in health worker deployment, especially in Bauchi, due to a preference for female midwives for ANC and deliveries. Distribution initiatives in the states are frequently short-lived 
because health workers quickly migrate from PHC to secondary or tertiary institutions in search of better opportunities. Staff preference for urban areas, political interference, favoritism by political "godfathers," and inadequate staffing are key factors thwarting re-distribution plans and government deployment efforts.

\section{Retention of Health Workers}

More than half of health managers from both states were unaware of any current retention policies in their state. Although there were set standards for measuring staff performance in both states, it appears these were not used to inform rewards and incentives, as two thirds of managers from both states reported that there were no incentives based on staff performance.

Delayed salary payments and arrears, unsatisfactory remuneration, workloads and staff shortages, poor retirement benefits and allowances, and lack of opportunities for development are all reasons why health workers leave the PHC system. Over one third of health workers in both states work more than 50 hours a week. Long working hours may be caused by inadequate staffing, and can inhibit motivation and result in further attrition. Further effects of excessive workloads include fatigue, burnout, and high staff turnovers. ${ }^{23}$

It is important to consider the implications of excess workload on health workers' willingness to assume more tasks and responsibilities, as the task shifting policy proposes. Attention must be paid to the nature of assignments being shifted, and care must be taken to ensure CHEWs are not overwhelmed. If CHEWs are overwhelmed at facilities, health promotion and prevention activities will suffer commensurately.

The frequent delays in salary payments may be occasioned by delays in federal government allocations. It is common for state civil servants to receive salary payments before local government employees, which has reportedly affected PHC worker motivation. De-centralizing the governance structure to facilitate prompt payment of PHC workers, or instituting a revolving fund to allow prompt salary payments, may be helpful. Payment of allowances, especially rural allowances, is crucial for retention of PHC workers. In Canada, rural allowance payments have been used to redistribute and retain health workers at rural facilities. ${ }^{24}$ There was consensus that bonding can be a useful strategy for addressing staff shortages in both states. Monitoring systems to track bonded employees and ensure they fulfil their commitments are required to ensure the system's potential benefits are actualized.

To retain health workers, more emphasis should be placed on task shifting and -sharing, as well as recruiting health workers to support the health workforce. One study suggested that co-managing and -financing PHC facilities with local members of the community could ensure better functioning and increasing health worker job satisfaction and retention. ${ }^{25}$ This aligns with this study's qualitative findings, whereby stakeholders perceive that posting health workers to their communities of origin will foster investment and accountability, both by health workers and the local community. 


\section{Policy Recommendations and Conclusion}

\section{Recommendations for Policy and Practice}

1. To better organize the hiring process, application forms should be accessible online, completed and submitted via the same portal, in addition to hard copy availability. Application forms should be free of charge, to foster equity and allow credible candidates to apply.

2. Notifications of interviews by two or more mechanisms, will prove more effective in reducing gaps created when only one means of communication issues invitations for interviews.

3. Governments should ensure newly hired staff receive a copy of their job descriptions including responsibilities, additional duties, and complete compensation package, with duplicate copies signed by supervisors or area managers and submitted to the Civil Service Commission.

4. Governments should ensure new hires are confirmed within two years of initial date of offer. Delays in confirming employment affect morale and may lead to attrition.

5. To limit political interference in the hiring process, spouses and direct relatives of government officials should declare such relationships on their application forms. The hiring process could be outsourced to an independent HR consultancy firm to improve adherence to recruitment protocols, before completion by the Civil Service Commission.

6. Governments should provide newly hired workers with staff manuals and civil service guidance to enrich their orientation and promote good conduct as civil servants. Drafting a code of conduct pertaining to recruitment, deployment, and transfer of relatives of senior government officials and politicians should be considered.

7. Rural posting allowances should be re-enacted and applied in both states.

8. Governments should institute scholarships for pre- and in-service education and training of health workers bonded to rural service. The mechanisms for bonding in both states should be revised to ensure bonding agreements are enforced. Governments should liaise with educational institutions to ensure a bonded employee's progress is regularly monitored.

9. State governments should adjust retirement age or onset of service (for those hired while within pre-service training) to improve length of service and thereby retention of these health workers.

10. Exit interviews should be conducted to create learning opportunities as a result of staff departures, to learn their motivations for leaving.

\section{Conclusion}

Strategies to improve HRH policy adherence are urgently needed to effectively address the gaps and ensure states can attract and retain a competent workforce to drive $\mathrm{PHC}$ service delivery and improve $\mathrm{MNCH}$ services.

\section{Study Limitations}

While the study makes substantial contributions to the knowledge base on HRH hiring, deployment, and retention in rural and remote areas, there are some key limitations worth mentioning. The study assessed personal accounts of recruitment, which may not fully reflect the current situation in the states. This limitation was partially addressed in multiple data collection strategies, to triangulate findings. Self-reporting by study respondents may result in over- or under-reporting; adequate training of interviewers and the assurances provided to study respondents that no identifiers would be used were employed to mitigate this. 


\section{References}

1. National Population Commission (NPC) [Nigeria] and ICF. 2013. Nigeria Demographic and Health Survey (NDHS). https://dhsprogram.com/pubs/pdf/FR293/FR293.pdf

2. WHO. Trends in maternal mortality: 1990-2015: Estimates from WHO, UNICEF, UNFPA, World Bank Group and United Nations Population Division. 2015;

3. Sloan NL, Storey A, Fasawe O, Yakubu J, McCrystal K, Wiwa O, et al. 2018. Advancing Survival in Nigeria: A Pre-post Evaluation of an Integrated Maternal and Neonatal Health Program. Maternal and Child Health Journal.

4. Okonofua F, Ntoimo L, Ogu R, Galadanci H, Abdus-salam R, Gana M, et al. 2018. Association of the client-provider ratio with the risk of maternal mortality in referral hospitals: a multi-site study in Nigeria. Reproductive Health 15(1): 32.

5. Federal Ministry of Health. 2006. National Human Resource for Health Policy.

6. Federal Ministry of Health. 2015. National Human Resource for Health Strategic Plan 20152019.

7. Federal Ministry of Health. 2017. National Strategic Health Development Plan 1: End Term Evaluation Report.

8. Federal Ministry of Health. 2012. Nigeria Health Sector Performance Report 2011.

9. Mbachu CO, Onwujekwe O, Chikezie I, Ezumah N, Das M, Uzochukwu BSC. 2016. Analysing key influences over actors' use of evidence in developing policies and strategies in Nigeria: a retrospective study of the Integrated Maternal Newborn and Child Health strategy. Health Research Policy and Systems 14(1): 27.

10. Kress DH, Su Y, Wang H. 2016. Assessment of primary health care system performance in nigeria: using the primary health care performance indicator conceptual framework. Health Systems and Reform 2(4): 302-318.

11. Williams A. 2014. The evolution of programs designed to increase utilization of skilled birth attendance in Nigeria. Science of Delivery Case Study.

12. Abimbola S, Okoli U, Olubajo O, Abdullahi MJ, Pate MA. 2012. The midwives service scheme in Nigeria. PLoS Med 9(5): e1001211.

13. Adegoke A, Utz B, Msuya SE, Van Den Broek N. 2012. Skilled Birth Attendants: who is who? A descriptive study of definitions and roles from nine Sub Saharan African countries. PLoS One 7(7): e40220.

14. Cooke JG, Tahir F. 2013. Maternal Health in Nigeria. Center for Strategic and International Studies.

15. Okoli U, Mohammed SA, Ejeckam C. 2016. Strengthening Primary Health Care Services in Rural Nigeria: The Potential of Using Midwives as Skilled Birth Attendants. Health Systems Policy Research 3: 2.

16. Kish, L. 1965. Survey Sampling. New York: John Wiley and Sons, Inc.

17. Ayamolowo SJ, Irinoye O, Oladoyin MA. 2013. Job satisfaction and work environment of primary health care nurses in Ekiti state, Nigeria: an exploratory study. International Journal of Caring Sciences 6: 531-42.

18. AMREF Kenya Human Resources For Health Project. 2012. Factors Affecting Motivation and Retention of Primary-Level Health Care Workers in Three Disparate Regions In Kenya. www.health.go.ke/wp-content/uploads/2015/09/HRH_Baseline_survey_-_final_report_5_1810-12_So.pdf 
19. Kolehmainen-Aitken R-L. 2004. Decentralization's impact on the health workforce: Perspectives of managers, workers and national leaders. Human Resoures for Health 2(1): 5. https://doi.org/10.1186/1478-4491-2-5

20. Federal Ministry of Health. 2008. National Human Resource for Health Strategic Plan 20082012.

21. World Health Organization. 2010. Increasing access to health workers in remote and rural areas through improved retention: Global policy recommendations.

22. Ebuehi OM, Campbell PC, Campbell OEP. 2011. Attraction and retention of qualified health workers to rural areas in Nigeria: a case study of four LGAs in Ogun State, Nigeria. Rural and Remote Health 11(1): 1515.

23. Gerein N, Green A, Pearson S. 2006. The implications of shortages of health professionals for maternal health in sub-Saharan Africa. Reproductive Health Matters 14(27): 40-50.

24. Fournier M. 2001. Les politiques de main-d'oeuvre médicale au Québec: bilan 1970-2000. Ruptures (revue Transdiscipl en santé) 7(2): 79-98.

25. Abimbola S, Olanipekun T, lgbokwe U, Negin J, Jan S, Martiniuk A, et al. 2015. How decentralisation influences the retention of primary health care workers in rural Nigeria. Global Health Action 8(1): 26616. 

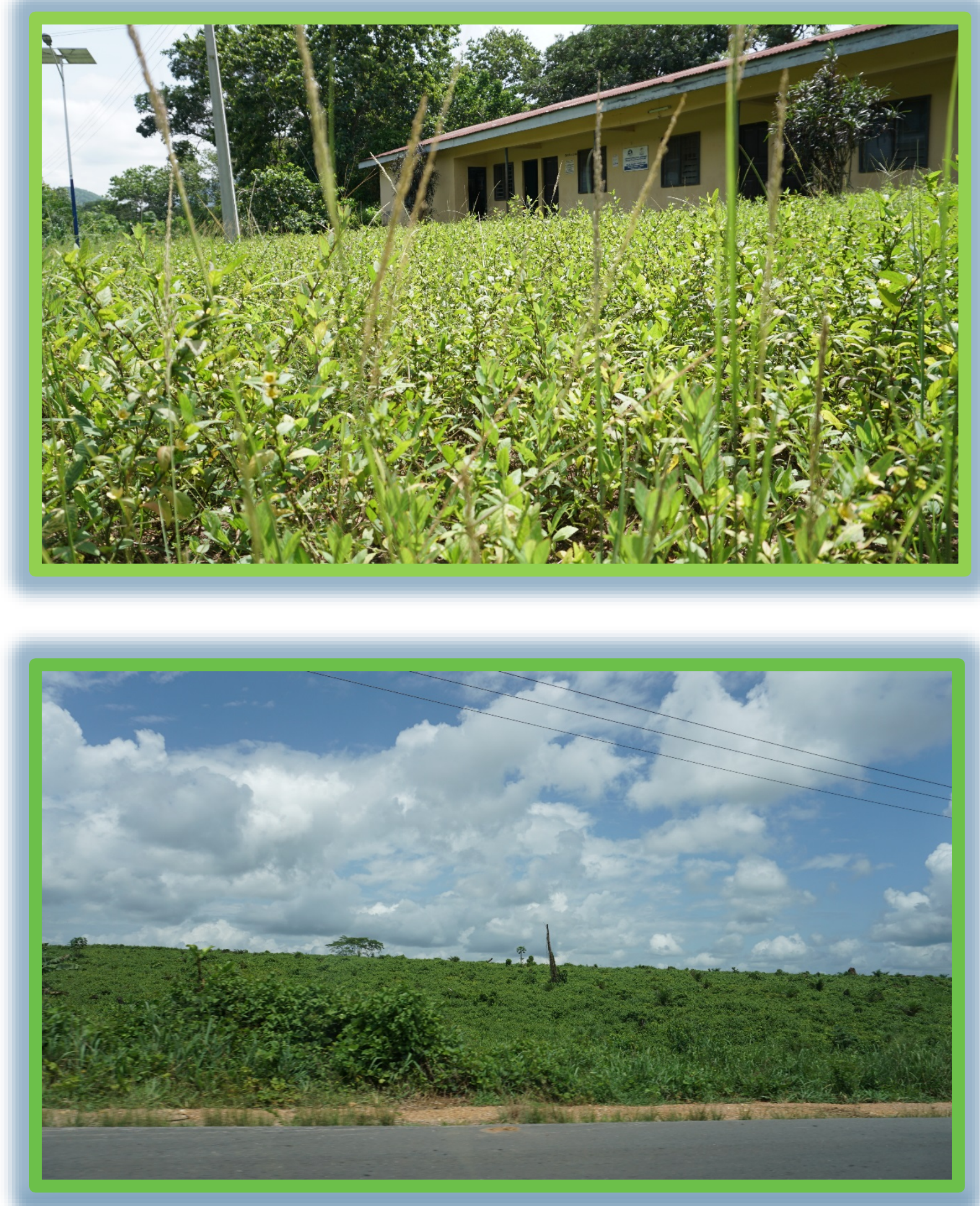

\section{POPULATION councli}

